\title{
Measuring biomarkers in wastewater as a new source of epidemiological information: current state and future perspectives
}

\begin{abstract}
AUTHORS:
Emma Gracia-Lor ${ }^{\mathrm{a}, \mathrm{b}^{*}}$, Sara Castiglioni ${ }^{\mathrm{b}}$, Richard Bade ${ }^{\mathrm{a}}$, Frederic Been ${ }^{\mathrm{c}}$, Erika Castrignanò ${ }^{\mathrm{d}}$, Adrian Covaci $^{\mathrm{c}}$, Iria González-Mariño ${ }^{\mathrm{b}}$, Evroula Hapeshi ${ }^{\mathrm{e}}$, Barbara Kasprzyk-Hordern ${ }^{\mathrm{d}}$, Juliet Kinyua ${ }^{\mathrm{c}}$, Foon Yin Laic, Thomas Letzel ${ }^{\mathrm{f}}$, Luigi Lopardo ${ }^{\mathrm{d}}$, Markus R. Meyer ${ }^{\mathrm{g}}$, Jake O’Brien ${ }^{\mathrm{h}}$, Pedram Ramin , Nikolaos I. Rousis ${ }^{\mathrm{b}}$, Axel Rydevik ${ }^{\mathrm{d}}$, Yeonsuk Ryu ${ }^{\mathrm{j}}$, Miguel M. Santos ${ }^{\mathrm{k}, 1}$, Ivan Senta ${ }^{\mathrm{m}}$, Nikolaos S. Thomaidis $^{\mathrm{n}}$, Sofia Veloutsou ${ }^{\mathrm{f}}$, Zhugen Yang ${ }^{\mathrm{o}}$, Ettore Zuccato $^{\mathrm{b}}$, Lubertus Bijlsma ${ }^{\mathrm{a}}$
\end{abstract}

${ }^{\text {a }}$ Research Institute for Pesticides and Water, Universitat Jaume I, Castellon, Spain

b IRCCS-Istituto di Ricerche Farmacologiche "Mario Negri", Department of Environmental Health Sciences, Milan, Italy

${ }^{\mathrm{c}}$ Toxicological Center, University of Antwerp, 2610 Wilrijk, Belgium

${ }^{\mathrm{d}}$ Deparment of Chemistry, Faculty of Science, University of Bath, Bath BA2 7AY, UK

${ }^{e}$ NIREAS-International Water Research Center, University of Cyprus, P.O. Box 20537, 1678 Nicosia, Cyprus

${ }^{\mathrm{f}}$ Analytical Group, Chair of Urban Water Systems Engineering, Technical University of Munich, Germany

${ }^{\mathrm{g}}$ Department of Experimental and Clinical Toxicology, Institute of Experimental and Clinical Pharmacology and Toxicology, Saarland University, 66421 Homburg, Germany

h National Research Center for Environmental Toxicology, The University of Queensland, Coopers Plains, QLD 4108, Australia

${ }^{i}$ Dept. of Environmental Engineering, Technical University of Denmark, Denmark

${ }^{\mathrm{j}}$ Ecotoxicology and Risk Assessment, Norwegian Institute for Water Research, Oslo, Norway

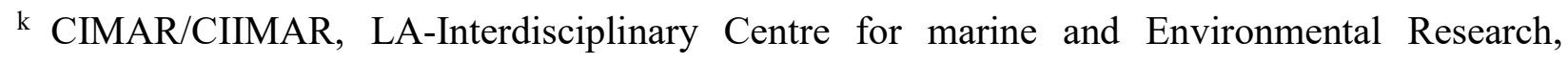
University of Porto, Portugal 
1 FCUP_Dept of Biology, Faculty of Sciences, University of Porto, Rua do Campo Alegre, 4169-007 Porto, Portugal

${ }^{\mathrm{m}}$ Rudjer Boskovic Institute, Zagreb, Croatia

${ }^{\mathrm{n}}$ Laboratory of Analytical Chemistry, Department of Chemistry, National and Kapodistrian University of Athens, Panepistimiopolis Zografou, 15771 Athens, Greece

${ }^{\circ}$ Division of Biomedical Engineering, School of Engineering, University of Glasgow, G128LT Glasgow, United Kingdom

* Corresponding author: Emma Gracia-Lor

E-mail: lor@uji.es; emma.gracialor@marionegri.it

\section{E-mail address of each author:}

Sara Castiglioni: sara.castiglioni@,marionegri.it

Richard Bade: bade@uji.es

Frederic Been: frederic.been@uantwerpen.be

Erika Castrignanò: E.Castrignano@bath.ac.uk

Adrian Covaci: adrian.covaci@uantwerpen.be

Iria González-Mariño: iria.gonzalez@usc.es

Evroula Hapeshi: hapeshi.evroula@ucy.ac.cy

Barbara Kasprzyk-Hordern: B.Kasprzyk-Hordern@bath.ac.uk

Juliet Kinyua: juliet.kinyua@uantwerpen.be

Foon Yin Lai: FoonYin.Lai@uantwerpen.be

Thomas Letzel: t.letzel@tum.de

Luigi Lopardo: 1.lopardo@bath.ac.uk 
Markus R. Meyer: markus.meyer@med.uni-heidelberg.de

Jake O’Brien: j.obrien2@uq.edu.au

Pedram Ramin: pear@env.dtu.dk

Nikolaos I. Rousis: nikolaos.rousis@marionegri.it

Axel Rydevik: a.rydevik@bath.ac.uk

Yeonsuk Ryu: Yeonsuk.Ryu@niva.no

Miguel M. Santos: santos@ciimar.up.pt

Ivan Senta: isenta@,irb.hr

Nikolaos S. Thomaidis: ntho@chem.uoa.gr

Sofia Veloutsou: sofia.veloutsou@tum.de

Zhugen Yang: Zhugen.Yang@glasgow.ac.uk

Ettore Zuccato: ettore.zuccato@marionegri.it

Lubertus Bijlsma: bijlsma@uji.es 


\begin{abstract}
The information obtained from the chemical analysis of specific human excretion products (biomarkers) in urban wastewater can be used to estimate the exposure or consumption of the population under investigation to a defined substance. A proper biomarker can provide relevant information about lifestyle habits, health and wellbeing, but its selection is not an easy task as it should fulfil several specific requirements in order to be successfully employed. This paper aims to summarize the current knowledge related to the most relevant biomarkers used so far. In addition, some potential wastewater biomarkers that could be used for future applications were evaluated. For this purpose, representative chemical classes have been chosen and grouped in four main categories: (i) those that provide estimates of lifestyle factors and substance use, (ii) those used to estimate the exposure to toxicants present in the environment and food, (iii) those that have the potential to provide information about public health and illness and (iv) those used to estimate the population size. To facilitate the evaluation of the eligibility of a compound as a biomarker, information, when available, on stability in urine and wastewater and pharmacokinetic data (i.e. metabolism and urinary excretion profile) has been reviewed. Finally, several needs and recommendations for future research are proposed.
\end{abstract}

\title{
Key words
}

Wastewater; Epidemiology; Biomarker; Consumption; Exposure; Population 


\section{INTRODUCTION}

Relevant epidemiological information about lifestyle habits, public health and wellbeing can be obtained from the chemical analysis of urban wastewater. This approach, called wastewater-based epidemiology (WBE), is based on the analysis of specific human metabolic excretion products (biomarkers) in wastewater as indicators of consumption or exposure of the population served by the sewer network under investigation to different substances. WBE has been successfully applied as a suitable approach for the estimation of illicit drugs consumption (Ort et al., 2014; Thomaidis et al., 2016; Thomas et al., 2012; van Nuijs et al., 2011a; Zuccato et al., 2008), but it has also recently been employed to assess other lifestyle-related factors such as alcohol (Rodríguez-Álvarez et al., 2015; Ryu et al., 2016), nicotine (Castiglioni et al., 2015b; Lopes et al., 2014; Rodríguez-Álvarez et al., 2014b), caffeine (Senta et al., 2015a) and new psychoactive substances (NPS) (Kinyua et al., 2015; Reid et al., 2014a; van Nuijs et al., 2014). WBE has also been applied to verify community-wide exposure to endocrine disruptors and antimicrobial agents in personal care and household products (O'Brien et al., 2015; Rydevik et al., 2015). The broad range of information that can be gathered from wastewater opens up the possibility of expanding WBE to other human biomarkers providing clues about diet, health, diseases and exposure to contaminants. For example by linking exposure to environmental or food contaminants with health outcomes such as diabetes or cancer.

In general, a human biomarker can be an endogenous compound (produced naturally in the body) or a metabolite of a xenobiotic/exogenous substance (produced through metabolic processes after intentional consumption of a substance, accidental exposure to environmental contaminants, as well as through diet or ingestion of a substance). Biomarkers can be classified on the basis of their function as biomarkers of exposure (compounds that give information about substances consumed or ingested) and biomarkers of effect (indicators of measurable changes or alterations in an organism that can be associated with health problems or wellbeing) and on the 
basis of biological nature (e.g. metabolites, hormones), or of the disease they can indicate (e.g. cardiovascular biomarkers, obesity biomarkers) (Pischon, 2009).

The selection of a specific biomarker is not an easy task, as it needs to satisfy different criteria (Figure 1) (Castiglioni and Gracia-Lor, 2015; Gracia-Lor et al., 2016). From a WBE perspective, a suitable biomarker must be excreted mainly via urine and concentration levels in urine should be at least in the $\mu \mathrm{g} / \mathrm{L}$ range to ensure its detection in raw wastewater after dilution (Chen et al., 2014).

Excreted via urine in consistent amounts

Detectable in wastewater

Stable in wastewater

Unique source: human metabolism

Low variance in the per capita daily excretion

Daily per capita excretion not affected by independent variables (season, weather or geographic location)
Requirements of:

- Lifestyle and substance use biomarkers

- Exposure biomarkers from environment and food

- Health biomarkers 
simulate physicochemical and microbial processes (Bisceglia and Lippa, 2014; McCall et al., 2016b; Ramin et al., 2016). It is important to note that biomarker transformation pathways in the sewer might be different from human metabolic pathways.

Furthermore, a biomarker should preferably be specific to the compound under investigation and unique to human metabolism, thus ensuring that its presence only derives from human excretion and not from exogenous sources (Daughton, 2012b). Therefore, pharmacokinetic data on human metabolism are necessary but unfortunately this information is not always feasible as for many substances it is very limited or do not even exist. This information, however, is highly relevant not only to back-calculate the consumption/exposure of/to a certain substance by a community, but also to distinguish the amount of a substance originating from human metabolism or other sources. Unfortunately, pharmacokinetic studies are time-consuming and have to fulfil strict ethical rules. Alternative approaches, which allow for the identification and selection of appropriate biomarkers, are therefore required; for example, in-vitro studies using liver enzymes, which metabolize the parent compound, help in the elucidation of the chemical structure of the metabolites formed (i.e. possible biomarkers) formed (Mardal et al., 2016). Computer-based in-silico modelling also allow the prediction of pharmacokinetics (Reid et al., 2014a). However these alternatives provide qualitative information on metabolism, but not data regarding excretion rates of parent substances and their metabolites (Gracia-Lor et al., 2016).

The present manuscript emerges within the framework of the pan-European interdisciplinary network (Sewage analysis CORE group-SCORE), which brings together experts from different disciplines interested in standardizing the WBE approach and in coordinating international studies (http://score-cost.eu/). The aim of this review is to describe the criteria for selecting suitable biomarkers and to give an overview of relevant human (urinary) metabolites and potential wastewater biomarkers. Biomarkers have been grouped in four sections: (i) those that provide estimates of lifestyle factors and substance use, (ii) those used to estimate the 
exposure to toxicants present in the environment and food, (iii) those giving information about public health and (iv) those used to estimate the population size. For each group and biomarker, a thorough review of the available pharmacokinetic data (i.e. metabolism and excretion profile) and stability in urine and wastewater (if known) is provided. This information can be used to evaluate their suitability according to the criteria described above. Finally, potential gaps or limitations are discussed and future research directions are proposed.

\section{LIFESTYLE AND SUBSTANCE USE BIOMARKERS}

Initially, WBE was applied to evaluate lifestyle, in particular illicit drug use within a community. Its ability to deliver objective and near-real-time data on drug use, being able to detect changes over time and local patterns of use, suggests that this method can be used as a complementary and extended data source to existing epidemiological tools. WBE has been well established for monitoring the use of cocaine, cannabis, amphetamine, methamphetamine and MDMA (3,4-methylenedioxymethamphetamine).

Additional applications to estimate consumption of other substances, such as alcohol, tobacco, caffeine and NPS, have been employed more recently. Alcohol and nicotine (tobacco) are probably the most popular and accepted recreational drugs. However, many negative social, economic and health aspects have been linked to their use, causing millions of deaths every year (World Health Organization, 2015, 2014). It is therefore important and of particular interest for policy makers to obtain continuous monitoring data on consumption levels and patterns of use, in order to reduce the disease burden related to alcohol and tobacco use. Caffeine use has been limitedly investigated, although it is one of the most extensively used legal stimulants, found in widely-consumed products, such as coffee, tea, soft and "energy" drinks. Besides monitoring its consumption, caffeine has also been proposed as a human biomarker for assessing the size and dynamics of the population served (see section 5.3) by a particular wastewater treatment plant (WWTP) (Senta et al., 2015a). NPS are emerging narcotic or psychotropic substances which may 
pose similar threats to public health such as classical illicit drugs (European Union, 2005; Papaseit et al., 2014). Due to the delay between their appearance on the market and their addition to the list of banned (or controlled) substances, many NPS can be legally purchased, thus promoting their proliferation worldwide. Furthermore, new substances appear continuously on the market (Bijlsma et al., 2016; EMCDDA, 2015a). WBE has been proposed as a tool for providing useful information on temporal and regional trends in the use of NPS.

Current state and some new features of WBE, with regard to lifestyle and substance use are presented in this chapter. Furthermore, specific biomarkers of each lifestyle factor are suggested (Table S1) and conceptual approaches for dealing with NPSs using biomarkers in wastewater are proposed.

\subsection{Illicit drugs}

Among the available epidemiological indicators, general population surveys have been traditionally used to assess illicit drug use at the population level. Yet, due to their inherent biases, complementary and real-time approaches are needed. The determination of illicit drug consumption through wastewater was first theorized by Daughton (Daughton, 2001) and implanted by Zuccato et al. using cocaine as an example (Zuccato et al., 2005). Since then, WBE has been widened to include other illicit drugs (Asimakopoulos and Kannan, 2016; Castiglioni et al., 2008; Hernández et al., 2016; van Nuijs et al., 2011a).

The biomarkers currently used are either the illicit drug itself (i.e. amphetamine, methamphetamine, and 3,4-methylenedioxy-methamphetamine-MDMA) or one of its metabolites (i.e. benzoylecgonine (BEG) for cocaine, 11-nor-9-carboxy-delta9tetrahydrocannabinol (THC-COOH) for cannabis and morphine or 6-acethylmorphine for heroin)

Cocaine, the first substance studied in WBE, is considered unstable in wastewater; however, its unique and stable metabolite (BEG) makes back-calculation to drug consumption 
more straightforward. It must be noted that significant degradation of BEG from cocaine in sewage is also reported (Plósz et al., 2013), which could result in over estimation of cocaine consumption if this formation is neglected. Considering human excretion rates, a cocaine: BEG ratio around 0.1 or lower can indicate consumption, and any value higher (between 0.1 and 0.7 ) could indicate other sources of cocaine, such as direct disposal (Castiglioni et al., 2011a). However, more research is needed in this regard (Bijlsma et al., 2012; Postigo et al., 2010; Van Nuijs et al., 2009).

$\Delta 9$-tetrahydrocannabinol (THC), the active ingredient of cannabis, is metabolized to more than 20 metabolites after consumption, with 11-nor- $\triangle 9$-carboxy-THC (THC-COOH) and 11hydroxy-THC (THC-OH) being those primarily excreted. THC-COOH has been shown to be highly stable and is thus normally used to estimate cannabis consumption, albeit with some analytical difficulties arising in multi-residue methods resulting from its non-polarity compared to other illicit drugs (Bijlsma et al., 2014; Ort et al., 2014; Pedrouzo et al., 2011).

Two more recently works studied illicit drugs are ketamine and methadone. Ketamine is a dissociative anaesthetic which has been used as a recreational drug, whilst methadone is a synthetic opioid used clinically to relieve pain and also as maintenance treatment of opioid addicts (Castiglioni et al., 2011b; Preston et al., 2003). Both ketamine and its metabolite norketamine are fairly stable in wastewater (Castiglioni et al., 2015a; McCall et al., 2016a), with the parent compound generally used as a biomarker for reliable estimation of drug usage. Variable stability for methadone has, however, been reported i.e. from high (Senta et al., 2014) to low (González-Mariño et al., 2010).

Opioids use in Europe remains a central issue, reflecting the significant impact these drugs still have on mortality and morbidity (EMCDDA, 2015b). In recent years, the production of high purity heroin has been rising, thereby increasing heroin-related mortality (UNODC, 2015). In the human body, heroin is rapidly hydrolyzed to 6-monoacetylmorphine (6-MAM) by blood esterases (Bencharit et al., 2003) and further hydrolyzed to morphine in the liver (Smith, 
2009). In wastewater, heroin shows low stability (González-Mariño et al., 2010). Although 6MAM detected in urine is used as a marker of heroin consumption (Staub et al., 2001), 6-MAM is not always detected in wastewater as it is not stable in wastewater (Thai et al., 2014). Backcalculations using 6-MAM as biomarker provides inconsistent results (Been et al., 2015). Therefore, morphine is considered as an alternative biomarker for heroin. However, therapeutic consumption of morphine should be subtracted from the total measured morphine in sewage (Khan and Nicell, 2011; van Nuijs et al., 2011a; Zuccato et al., 2016), which necessitates the availability of registered prescribed morphine at the time of wastewater sampling. Morphine is also formed in the sewer due to deconjugation of morphine glucuronide and deacetylation of 6MAM, which imposes new challenges in back-calculation schemes. Although fractions of morphine originating from codeine can be considered negligible (Zuccato et al., 2008), more research is needed to find a drug biomarker for heroin which fulfils all the aforementioned criteria.

As shown in Table 1, the most frequently used illicit drug biomarkers are benzoylecgonine, amphetamine, methamphetamine, MDMA and THC-COOH (Thomas et al., 2012). Information about excretion and stability in urine and wastewater of these and other illicit drug biomarkers less frequently studied is presented in Table S1.One of the most current analytical challenges associated with WBE is represented by chirality. Amphetamine, methamphetamine and MDMA are among the illicit drugs that are chiral and as a result they can exist as enantiomers (one enantiomeric pair per each chiral centre). The verification of their chiral signature in wastewater (i.e. relative proportion of two enantiomers within each enantiomeric pair) allows to distinguish between illicit or licit use and direct disposal (Emke et al., 2014). It has been shown that the distinction between the consumption or the disposal of MDMA could be made by differentiating the loads of the enantiomers present in wastewater. Indeed, enantiomeric fractions (EFs) greater than 0.5 indicated illicit use, whilst EFs equal to 0.5 indicated direct disposal, when EF was calculated as follows: 


$$
E F=\frac{(-)-M D M A}{(-)-M D M A+(+)-M D M A}
$$

Enantiomeric profiling of MDMA's metabolites were recently investigated in wastewater by Castrignanò et al., suggesting enantioselective metabolism for HMMA (Castrignanò et al., 2016). Amphetamine and methamphetamine can also be investigated at enantiomeric level, however due to both legal and illicit uses, a clear understanding between consumption and direct disposal is difficult (Emke et al., 2014; Kasprzyk-Hordern and Baker, 2012).

\subsection{Alcohol}

Following the consumption of alcoholic beverages, the majority of ingested ethanol is rapidly metabolized in the human body in a two-stage oxidation process, first to acetaldehyde and then to acetic acid. The remaining part is excreted unchanged in urine, sweat and exposed breath (Jones, 1990). However, a very small fraction $(<0.1 \%)$ undergoes a conjugation reaction with glucuronic acid to produce ethyl glucuronide (EtG) (Dahl et al., 2002) and with 3'phosphoadenosine 5'-phosphosulfate to produce ethyl sulphate (EtS) (Helander and Beck, 2005). These metabolites are excreted within a few hours and are detectable in urine for considerably longer times (up to 1-2 days, depending on the subject and the alcohol dose) (Helander and Beck, 2005; Høiseth et al., 2008), making them unequivocal indicators of recent alcohol consumption (Dahl et al., 2011; Dresen et al., 2004).

EtG was found to degrade $\sim 50 \%$ after 18 hours, whereas EtS showed little or no degradation (Reid et al., 2011). In addition, no significant differences were found between its stability in sewage and in an ethanol-fortified wastewater sample (Reid et al., 2011), indicating that it is unlikely to be formed from unconsumed alcohol discarded into the sewer system. Taking into account these observations, EtS has been used by several researchers to estimate community-wide alcohol consumption through wastewater analysis (Table 1). Typically, its 
determination in this matrix is performed by direct injection, after filtration and/or centrifugation, into a liquid chromatography-mass spectrometry system. The alcohol consumption rates estimated through WBE have revealed specific drinking patterns, temporal and spatial variations. The study conducted by Reid et al. (Reid et al., 2011), for example, clearly showed the weekend elevated drinking pattern in Oslo. Furthermore, the estimated consumption rates were in good agreement with sales statistics (Reid et al., 2011). The increase in alcohol consumption during the weekend was also found in three Spanish cities, eight Belgian cities an done Italian city (Andrés-Costa et al., 2016; Boogaerts et al., 2016; Mastroianni et al., 2014; Rodríguez-Álvarez et al., 2015, 2014a; Ryu et al., 2016). However, a different consumption pattern was observed during a special event in Valencia, where an increased alcohol use was noticeable, reaching the maximum rate on Wednesday, which corresponded to the last day of the "Fallas" festivities (Andrés-Costa et al., 2016). Co-consumption of alcohol and cocaine was also evaluated through WBE by analyzing cocaethylene, a specific biomarker excreted when the two substances are consumed together (Mastroianni et al., 2014; Rodríguez-Álvarez et al., 2015). In the studies carried out in Belgium (Boogaerts et al., 2016) and Greece (Gatidou et al., 2016) higher alcohol consumption in urbanized cities than in smaller villages was evidenced. Although all these studies highlight the potential of EtS as a reliable biomarker for estimating alcohol consumption in relative terms, the main limitation is the uncertainty associated with its percentage of excretion, which might lead to inaccurate back-calculations in absolute amounts. Until now, there have been insufficient pharmacokinetic studies evaluating this percentage to provide a unique, representative figure (Halter et al., 2008; Høiseth et al., 2008; Lostia et al., 2013; Schneider and Glatt, 2004; Wurst et al., 2006). In the aforementioned WBE studies, the range $0.010-0.016 \%$ (on molar basis) was used by (Andrés-Costa et al., 2016; Reid et al., 2011); the median value of the excretion rates provided by Høiseth et al. (Høiseth et al., 2008), 0.011\%, was used by (Mastroianni et al., 2014; Rodríguez-Álvarez et al., 2014a). Finally, four studies (Boogaerts et al., 2016; Gatidou et al., 2016; Rodríguez-Álvarez et al., 2015; Ryu et al., 2016), 
employed a people-weighted value of $0.012 \%$, based on the data provided by (Høiseth et al., 2008) and (Wurst et al., 2006).

\subsection{Tobacco}

Nicotine is the principal alkaloid found in tobacco and, although not being directly associated with diseases, its addictiveness is the major cause of continued use of tobacco products (Hukkanen, 2005). Nicotine is extensively metabolized in humans, with $70-80 \%$ of the initial dose being converted to cotinine (Benowitz and Jacob, 1994), which is then further metabolized into various compounds, the most abundant being trans-3'-hydroxycotinine (Byrd et al., 1992). Nicotine and its major metabolites are also excreted as glucuronides. Globally, nicotine is excreted unchanged at rates between 8 and 10\%, whilst its glucuronide makes up for $3-5 \%$ of the initial dose (Byrd et al., 1992). Cotinine and its glucuronide are excreted at rates between $10-15 \%$ and $12-17 \%$, respectively, while trans-3'-hydroxycotinine and its glucuronide make up for $33-40 \%$ and $7-9 \%$ of the initial dose, respectively (Hukkanen, 2005).

Nicotine and its metabolites, cotinine and trans-3'-hydroxycotinine, have been analyzed in wastewater as biomarkers (Table S1) to estimate tobacco use in various communities (Castiglioni et al., 2015b; Lopes et al., 2014; Mackul'ak et al., 2015; Rodríguez-Álvarez et al., 2014b; Senta et al., 2015a). The three compounds were shown to be stable in wastewater samples stored at $4^{\circ} \mathrm{C}$ and $20^{\circ} \mathrm{C}$ during $24 \mathrm{~h}$ (Chen et al., 2014; Rodríguez-Álvarez et al., 2014b; Senta et al., 2015a). However, the concentration of the glucuronide of trans-3'hydroxycotinine was shown to decrease even in refrigerated samples (i.e., $35 \%$ decrease over $8 \mathrm{~h}$ at $4^{\circ} \mathrm{C}$ ). The authors of the study thus suggested to enzymatically deconjungate the compounds prior to extraction and analysis (Rodríguez-Álvarez et al., 2014b).

The amounts of these compounds in wastewater range from 0.1 to $7 \mu \mathrm{g} / \mathrm{L}$ (Buerge et al., 2008; Mackul'ak et al., 2015; Rodríguez-Álvarez et al., 2014b; Senta et al., 2015a), and the levels of cotinine and trans-3'-hydroxycotinine reflected the excretion profiles expected from 
pharmacokinetic studies, whilst nicotine was found at higher levels (Rodríguez-Álvarez et al., 2014b; Senta et al., 2015a). The contribution from ashes and cigarettes butts has been advanced as a possible explanation for this observation (Castiglioni et al., 2015b; Rodríguez-Álvarez et al., 2014b; Senta et al., 2015a). In fact, higher nicotine levels have been reported during rain events, supporting the hypothesis that ashes and cigarette butts found on streets eventually contribute to measured nicotine loads (Senta et al., 2015a). Thus, cotinine and trans-3'-hydroxycotinine were used as biomarkers to estimate the amount of nicotine used per capita in a population, as indicated in Table 1 (Castiglioni et al., 2015b; Mackul'ak et al., 2015; Rodríguez-Álvarez et al., 2014b; Senta et al., 2015a).

In some studies, figures were corrected to account for the portion of nicotine absorbed during smoking (Castiglioni et al., 2015b; Mackul'ak et al., 2015), thus providing estimates of the gross amount of number of cigarettes. Additionally, Mackul'ak and co-workers (Mackul'ak et al., 2015) included a factor to account for losses due to degradation, based on the mean residence time of wastewater in sewers. From the estimated nicotine consumption, the number of cigarettes smoked per capita was also calculated using as reference value $0.8 \mathrm{mg}$ of nicotine per cigarette (Gorrod and Wahren, 1993; Lopes et al., 2014; Rodríguez-Álvarez et al., 2014b) or 1.25 mg of nicotine (Castiglioni et al., 2015b). The obtained figures highlighted substantial differences in consumption within the same country. For example, researchers from Italy found significant differences between the north, centre and south of the country (Castiglioni et al., 2015b; Senta et al., 2015a). These results were in agreement with epidemiological data, which suggested a higher prevalence of tobacco use in the south (Castiglioni et al., 2015b). Similarly, important differences were found in cities in Slovakia and Spain (Mackul'ak et al., 2015; RodríguezÁlvarez et al., 2014b). In Portugal, estimates of nicotine consumption derived from wastewater analysis were in line with findings from a European survey (Lopes et al., 2014).

Mass loads measured in wastewater were also used to investigate weekly consumption patterns and findings suggested that this was stable throughout the week (Chen et al., 2014; 
Rodríguez-Álvarez et al., 2014b; Senta et al., 2015a). Public holidays and specific touristic locations, attracting larger crowds, were the only exceptions (Lopes et al., 2014; Mackul'ak et al., 2015).

The results obtained show that the measurement of nicotine metabolites is a useful tool which could potentially be used to complete current knowledge about the prevalence of tobacco use.

\subsection{Caffeine}

Caffeine (1,3,7-trimethylxanthine) is the world's most widely consumed stimulating agent (Garattini, 1993). It is found in many globally popular products, including tea and cola drinks, as well as in some medications and dietary supplements, but the most important source of this alkaloid is coffee.

Caffeine metabolism is extensive (Baselt, 2004), with at least 17 urinary metabolites identified in humans (Garattini, 1993). The major metabolites include 1-methyluric acid (excretion rate 12-25\%), 1-methylxanthine (9-18\%), 7-methylxanthine (2-8\%), paraxanthine (1,7-dimethylxanthine; 4-7\%), 1,7-dimethyluric acid (5-8\%) and unstable product 5acetylamino-6-formylamino-3-methyluracil (4-15\%), with a small percentage (1-4\%) of the initial dose excreted as the parent compound (Carrillo and Benitez, 1994; Garattini, 1993). The list of caffeine metabolites identified in humans, together with the excretion rates can be found in Table S1. Besides being complex, caffeine metabolism is also rather variable, with the different excretion rates observed not only in different studies, but also between individuals within the same studies (Carrillo and Benitez, 1994; Grant et al., 1983). These variations can be related with genetic differences (Blanchard et al., 1985; Grant et al., 1983) or influenced by other factors, such as age (Blanchard et al., 1985; Grant et al., 1983), pregnancy ((Carrillo and Benitez, 1994; Garattini, 1993) or medications (Callahan et al., 1983). However, certain metabolites, such as paraxanthine, 1,7-dimethyluric acid and 1-methylxanthine were found to be less affected by 
the genetic background compared to the parent compound and they were, therefore, suggested as potential biomarkers for caffeine dietary intake (Crews et al., 2001). Furthermore, most of the pharmacokinetic data on caffeine metabolism in humans are quite old (Blanchard et al., 1985; Grant et al., 1983) and some of them include a relatively low number of subjects (Blanchard et al., 1985).

Due to its wide usage in modern societies, caffeine is among the most ubiquitous wastewater micro-contaminants, usually detected at relatively high concentration levels $(\mu \mathrm{g} / \mathrm{L})$ in untreated wastewater (Martínez-Bueno et al., 2011; Rosal et al., 2010; Santos et al., 2009). Due to this, caffeine was proposed as anthropogenic marker to indicate the discharge of domestic wastewater in rivers and lakes (Buerge et al., 2003), but so far has been rarely used as a biomarker in a WBE approach. Caffeine has also been proposed as a human biomarker for assessing population size and the dynamics of people served by a particular WWTP (Daughton, 2012b) (see section 5.3).

However, with the exception of paraxanthine, data on the occurrence of caffeine metabolites in wastewater are still very scarce. In fact, the first comprehensive study which included most of the major caffeine metabolites (1-methylxanthine, 7-methylxanthine and paraxanthine) was published just recently (Senta et al., 2015a). Concentrations of these metabolites found in Italian wastewater were similar to those of the parent compound, i.e. in the $\mu \mathrm{g} / \mathrm{L}$ range. In the same work temporal and spatial patterns of use were also studied and the mean mass loads of caffeine and its major metabolites revealed to be slightly lower during the weekend, probably due to the lower consumption of coffee. Similar findings for caffeine was reported by Rico et al. (Rico et al., 2016; Senta et al., 2015a). On the other hand, no clear geographical trends could be observed. Besides being easily detectable, caffeine, 1methylxanthine, 7-methylxanthine and paraxanthine fulfill additional important requirement for an ideal biomarker - they are stable in wastewater samples stored at $4{ }^{\circ} \mathrm{C}$ and $20{ }^{\circ} \mathrm{C}$ for $24 \mathrm{~h}$ (Senta et al., 2015a). However, it is noteworthy that more research is needed in order to select 
the most suitable caffeine biomarker in wastewater for the correct interpretation of the obtained results within the concept of WBE.

\subsection{New Psychoactive Substances}

The detection of NPS and the estimation of their use are especially challenging for drug epidemiology, since new compounds appear continuously on the market and consumers do not always know the composition of the drugs they take. WBE can shed some light and provide additional information, but it is also affected by important challenges. First, pharmacokinetic data are essentially non-existent for most NPS, making it extremely difficult to define appropriate biomarkers. Second, the prevalence of abuse of a single substance is generally low, leading to very low concentrations in wastewater. Finally, their stability in this matrix is largely unknown (EMCDDA, 2016; Reid and Thomas, 2016). Based on the limited information available, this section attempts to present a selection of potential biomarkers, to be used in WBE studies, for the most common classes of NPSs: synthetic cannabinoids, synthetic cathinones, phenethylamines, piperazines, tryptamines, arylcycloalkylamines and benzodiazepines (EMCDDA, 2015a). The two first groups constitute the largest categories and also account for the majority of seizures in Europe (EMCDDA, 2015a).

Synthetic cannabinoids include a broad range of structurally different compounds sharing affinity for the cannabinoid receptors in the brain (Pertwee, 2008). Due to their recent increased popularity, their human metabolism is a growing area of research. Several in vitro and in vivo experiments have been performed over the past few years and, although individual pharmacokinetic profiles remain to be elucidated for many of them, it is generally thought that synthetic cannabinoids are extensively oxidized in the human body and excreted as a complex mixture of phase I and phase II metabolites (Fantegrossi et al., 2014; Seely et al., 2012). JWHtype cannabinoids are the most popular drugs within this class. Monohydroxylation, either at the $\mathrm{N}$-alkyl side chain, the naphthyl moiety or the indole moiety (followed by the corresponding 
glucuronidation) has been identified as their major metabolic pathway and, in fact, monohydroxylated metabolites have been detected in urine from JWH-type cannabinoids consumers (Hutter et al., 2012; Ozturk et al., 2015; Wohlfarth et al., 2013). However, the lack of rigorous pharmacokinetic data, essential to calculate excretion rates, prevents from extrapolating these analyses to whole communities by the WBE approach. Another important limitation concerns their instability in wastewater: the scarce literature available suggests that some synthetic cannabinoids and their metabolites are highly labile and tend to get adsorbed to particle matter, hindering their determination and sub-estimating the potentially derived abuse calculations (Reid et al., 2014a, 2014b). As a reflection of these intrinsic difficulties, to the best of our knowledge only the metabolite JWH 018 N-5-hydroxypentyl and the parent compounds JWH-210 and JWH-122, have been positively detected in wastewater in two out of all the studies dealing with NPS in this matrix (Borova et al., 2015; Reid et al., 2014b) (see Table S1).

Synthetic cathinones are known to have been abused for approximately 15 years and the synthesis of cathinone derivatives has been reported since the late 1920s (Hyde and Adams, 1928; Prosser and Nelson, 2012). They all refer to cathinone ((S)-2-amino-1-phenyl-1propanone), a naturally occurring stimulant found in the leaves of Catha edulis (Khat) (Prosser and Nelson, 2012). In general, the drugs are in part extensively metabolized in humans. However, some of the synthetic cathinones are also excreted unchanged in urine (Uralets et al., 2014). Details on the metabolism and detectability of synthetic cathinones can be found in original articles and are summarized in several review articles (Ellefsen et al., 2015; Helfer et al., 2007; Meyer et al., 2014, 2012, 2010a, 2010b; Meyer and Maurer, 2010; Pawlik et al., 2012; Pozo et al., 2014; Shima et al., 2014; Staack and Maurer, 2005; Uralets et al., 2014; WelterLuedeke and Maurer, 2015). Also, data on the stability, especially under storage conditions, were published (Senta et al., 2015b) and highlighted the possible instability of the parent compounds under alkaline conditions (Johnson and Botch-Jones, 2013; Tsujikawa et al., 2012). However, detailed and comprehensive studies are missing on their chemical stability in wastewater and 
also biotransformation in the sewer or wastewater should be considered (McCall et al., 2016a). Several studies were published on the analysis of synthetic cathinones in wastewater samples, with mephedrone, methylenedioxypyrovalerone, methcathinone, methylone and $\alpha$ pyrrolidinovalerophenone ( $\alpha$-PVP) being the most frequently detected (Borova et al., 2015; Chen et al., 2013; González-Mariño et al., 2016a, 2016b; Kinyua et al., 2015; Mwenesongole et al., 2013; Ocaña-González et al., 2015; Thai et al., 2016; Tscharke et al., 2016).

Phenylethylamines are a class of substances related to amphetamine and methamphetamine, possessing psychoactive and stimulant effects; however, modification of these compounds can lead to potent hallucinogens (Zaitsu et al., 2011; Zawilska and Andrzejczak, 2015). They include amphetamine derivatives such as MDMA, 2C and 'D' series drugs. However, the phenethylamine core is shared among several compounds including cathinones and catecholamines. Several metabolism studies have been conducted in an effort to understand their metabolic profiles (Ewald et al., 2008, 2006; Lai et al., 2015b; Staack et al., 2003) but more information is needed.

Piperazine-like compounds include the original member 1-benzylpiperazine (BZP), its methylenedioxy analogue and several phenylpiperazines. They are mainly known to bind to serotonin receptors, with BZP additionally producing amphetamine-like stimulant effects (Bye et al., 1973; De Boer et al., 2001). A summary with details on the metabolism of piperazines can be found in some articles (Maurer et al., 2004; Staack et al., 2001; Staack and Maurer, 2005); furthermore, one study showed the detection of metabolites in human urine (Tsutsumi et al., 2005). Some examples are shown in Table S1.

Tryptamine is a primary amine alkaloid found widely in nature in both the plant and animal kingdoms and known for its hallucinogenic effects (Collins, 2011). Metabolism of some synthetic tryptamines has been studied (Kamata et al., 2006; Michely et al., 2015; Narimatsu et al., 2008). 
Arylcycloalkylamines, which include the ketamine derivative methoxetamine (MXE) and phencyclidine derivatives, have emerged as legal alternatives to ketamine (Roth et al., 2013). MXE, which has gained popularity in several European countries (EMCDDA, 2014), is extensively metabolized (Meyer et al., 2013) but it was detected as parent MXE in wastewater from Belgium and Switzerland (Kinyua et al., 2015).

Benzodiazepines are psychoactive substances whose core structure is a benzene ring fused to a diazepine ring. Benzodiazepines are known as tranquilizers and are among the most commonly prescribed antidepressant medications. Although a useful pharmaceutical, there is potential for abuse due to their hypnotic and sedative effects - even to the extent of being used as "date rape" drugs (Schwartz et al., 2000). From now on we will refer to those benzodiazepines used illegally as design benzodiazepines._Designer benzodiazepines have become a rapidly growing class of drugs on the NPS online market, since a medical prescription is not needed. Since designer benzodiazepines have increased in popularity, studies have been conducted characterizing their human metabolism (Huppertz et al., 2015; Moosmann et al., 2013).

Up to now, no designer phenethylamines, tryptamines or designer benzodiazepines and metabolites have been detected in wastewater and only two studies has reported the stability of some phenylethylamines in wastewater (Bade et al., 2016; Senta et al., 2015b).

Although the interpretation of quantitative results should be done carefully for NPS due to the lack of metabolic information, the qualitative monitoring could lead to a better understanding of the frequency of use and could identify changes in consumption.

\section{EXPOSURE BIOMARKERS FROM ENVIRONMENT AND FOOD}

Two important exposure pathways for potentially harmful compounds are the dietary intake and the exposure from the surrounding daily environment. The monitoring of various classes of compounds for which exposure commonly occurs through these routes is necessary to safeguard public health. Representative chemical classes have been chosen as examples for this 
paper. Pesticides, mycotoxins and parabens are three classes of compounds for which exposure occurs through the intake of contaminated food or absorption through the skin and adverse health effects can be foreseen for humans (Błędzka et al., 2014; Heyndrickx et al., 2015; Rizzati et al., 2016; Warth et al., 2013). Exposure through the indoor environment (furniture, electronics, packaging and personal care products (PCPs)) is characteristic for UV-filters, plasticizers and brominated flame retardants.

This section reviews the specific biomarkers of each of the above mentioned chemical classes which could be measured in wastewater in order to assess the overall exposure to these compounds through a WBE approach. When relevant, we have also included the metabolites of these chemicals to be explored as a suitable biomarker. The suggested biomarkers are reported in Table S2 including also metabolites, whenever such information is available.

\subsection{Pesticides}

Pesticides are chemicals commonly used for control of harmful organisms, such as fungi, insects and weeds. They are mostly used for crop protection, but can also be used for livestock protection, as well as for other industrial and household purposes, such as termite prevention. The general population is exposed to pesticides mainly through diet (Ntzani et al., 2013), but also through household use (Trunnelle et al., 2013) and inhalation of polluted air - particularly in agricultural areas where aerial spraying of pesticides occurs (Coscollà et al., 2010). Exposure to pesticides is of public concern as they may cause health effects such as elevated rates of chronic diseases, like cancer or diabetes, as well as neurodegenerative disorders such as Parkinson disease, birth defects and reproductive diseases (Rizzati et al., 2016). Young children are the most susceptible to be at risk (European Food Safety Authority, 2013).

There are several types of pesticides and they are generally classified by their chemical structure: carbamate, organophosphate or triazine pesticides (Table S2). They may also be classified by the type of pest they control, such as herbicides, which are intended to kill weeds 
and other unwanted plants, and insecticides, which kill insects and other arthropods. Pesticides are mostly formulated as mixtures with individual components which may act independently of each other, interact or have dose-addition effects (Hernández et al., 2013).

Until now, there are only two WBE studies (Rousis et al., 2016a, 2016b) published on human exposure to pesticides. The first work (Rousis et al., 2016a) proposed for the first time a new application for pesticides, where pyrethroid, triazine and organophosphate metabolites were monitored in influent wastewater of seven Italian cities. The most frequently detected compounds were the specific metabolite of chlorpyrifos and chlorpyrifos-methyl, 3,5,6-trichloro2-pyridinol (TCPY), the metabolite of diazinon (2-isopropyl-6-methyl-4-pyrimidinol, IMPY), the pyrethroid metabolites 3-phenoxybenzoic acid (3-PBA, common metabolite of about 20 pyrethroids), 3-(2,2-dichlorovinyl)-2,2-dimethyl-(1-cyclopropane)carboxylic acid (DCCA, common metabolite of permetrin, cypermetrin and cyflutrin) and two alkyl phosphate metabolites. The second work (Rousis et al., 2016b) applied the novel WBE approach to assess further exposure to pyrethroids, concretely 3-PBA, cis-DCCA and trans-DCCA. The obtained results were in agreement with the Human Biomonitoring (HBM) profiles in urine samples of the general population, reported in the literature.

Yusa et al. 2015 reviewed analytical methods for HBM of pesticides and found that the most commonly biomonitored ones are carbamates, herbicides, neonicotinoids, organophosphates, pyrethroids and sulfonylurea herbicides - all of which can be monitored in urine samples and they can be good potential biomarkers for WBE. However, some other pesticide classes, such as organochlorines, are probably not suited to WBE due to their non-polar characteristics and their poor excretion in urine (Yusa et al., 2015).

As described previously for other substances, the metabolites of pesticides rather than the parent substances should be measured in wastewater to avoid contributions from sources other than human metabolism. It has to be emphasized that some pesticide metabolites are also formed in the environment (i.e. atrazine undergoes dealkylation in water systems forming human 
metabolites) and therefore more research is needed. Moreover, there are some common metabolites produced by different classes of compounds, such as organophosphate pesticides, organophosphate plasticizers and flame retardants, and this should be taken into account in a WBE approach. The novel method developed by Rousis et al. is considered as a valuable tool for obtaining objective, direct information on pesticide exposure levels and could provide complementary information for HBM studies. Table S2 presents the main potential biomarkers of exposure to pesticides selected by considering the detection frequency in urine, and the concentration levels (Barr, 2008; Yusa et al., 2015).

\subsection{Mycotoxins}

Mycotoxins are toxic fungal metabolites that can be found in food and feed which are intended for human and animal consumption (i.e. cereals such as rice, maize and wheat). There is huge concern of human health risks related to the ingestion of these substances, since they are stable in food processing and cooking. Maximum tolerable levels in food commodities were therefore legally established in many countries (Comission Regulation 1881/2006, 2006). While, nowadays, approximately 400 compounds belong to this group, only 10-15 are considered to be priority mycotoxins, due to higher occurrence and toxicity. These latter compounds belong to the groups of aflatoxins, ochratoxins, patulin and fusarium toxins (tricothecenes, fumonisins, zearalenone and zearalenone derivatives) (Anfossi et al., 2016; Turner et al., 2015). HBM studies performed on general population have shown that the most studied mycotoxin biomarkers in urine samples are aflatoxin M1 (AFM1), ochratoxin A (OTA), deoxynivalenol (DON), nivalenol (NIV), fumonisin B1 (FB1) and zearalenone (ZON) (H Fromme et al., 2016; Heyndrickx et al., 2015). If mycotoxin contaminations are going to be increased in the near future due to higher global food demand and global climate and environment changes, new methods are needed to evaluate the human exposure to mycotoxins (Marroquín-Cardona et al., 2014). Thus, a novel 
approach such as the WBE can be useful to provide complementary information to existing methods.

Few studies dealing with the determination of mycotoxins in wastewater have been published. The studied analytes were detected at very low concentrations (few ng/L), but at high detection frequency. In addition to parent compounds, some human metabolites were also investigated. The detected mycotoxins were DON, beauvericin (BEA), 3-Acetyldeoxynivalenol (3-AcDON), NIV, ZON, $\alpha$-zearalenol ( $\alpha$-ZOL) and $\beta$-zearalenol ( $\beta$-ZOL) (Kolpin et al., 2014; Laganà et al., 2004; Schenzel et al., 2012, 2010; Wettstein and Bucheli, 2010). None of these studies attempted to apply the WBE approach to these substances; they had only a monitoring scope. In the present paper a selection of mycotoxins and their related potential biomarkers for a WBE approach were reported for the first time (Table S2).

\subsection{Parabens}

Parabens are a group of chemicals that is drawing a lot of interest in the current discussion given their potential endocrine disrupting properties, since studies have shown that they have potential adverse health effects (Hu et al., 2013; Kim et al., 2015; Zhang et al., 2013). This has raised concern considering their widespread use. Parabens are used as preservatives in many different products, such as cosmetics, PCPs and foods, and can be commonly found in household products.

Some studies also investigated the occurrence and fate of parabens in wastewater (González-Mariño et al., 2009; Gracia-Lor et al., 2012a; Kasprzyk-Hordern et al., 2008), but not from a WBE perspective. Therefore, a list of known urinary biomarkers for paraben exposure is reported in Table S2. Future research should be addressed in order to explore paraben biomarkers for WBE.

\subsection{UV-Filters}


Overexposure to ultraviolet (UV) radiation has been associated with skin disorders, such as cancer (Ramos et al., 2016). This led to the widespread usage of UV filters in a variety of personal care products to protect against UV radiation, i.e., sunscreen, cosmetics, beauty creams, body lotions, hair sprays and shampoos (Brausch and Rand, 2011). UV filters are also used in food packages, plastics and textiles to prevent polymer degradation. Hence, human exposure occurs through multiple routes such as dermal absorption, ingestion of contaminated food and tap water (Valle-Sistac et al., 2016). Two major types of UV filters are currently available; organic UV filters are used to absorb UVA and/or UVB radiation, whereas inorganic UV filters mainly reflect the radiation. Given the high photostability and lipophilicity, many UV filters can enter biological membranes and bioaccumulate in the body, including in the placental tissues (Valle-Sistac et al., 2016). However, it is important to note that most UV-Filters are released into the sewers without going through the body (Daughton and Ruhoy, 2009; Ruhoy and Daughton, 2008). This fact would contribute to a large uncertainty in its estimation.

Urinary analysis has frequently detected UV filters at various levels, demonstrating human exposure (Dewalque et al., 2014; Louis et al., 2015). Despite their widespread use, between 2010 and 2015 only 20 studies have been published in peer reviewed journals dealing with UV filters detection in wastewater (Ramos et al., 2016). Yet, available data indicates that major UV filters groups, i.e. benzophenone derivatives, p-aminobenzoic acid derivatives, camphor derivatives, benzotriazole derivatives, salicylate derivatives, benzimidazole derivatives, triazine derivatives, cinnamate derivatives, crylene derivatives, and dibenzoyl methane derivatives, are ubiquitous in wastewater with concentrations ranging from the $\mathrm{ng} / \mathrm{L}$ to the $\mathrm{mg} / \mathrm{L}$ level (Gago-Ferrero et al., 2011; Rodil et al., 2012). Evidence from mammalian studies indicate that various UV filters are endocrine disruptors, acting as estrogenic, antiestrogenic, antiandrogenic or antithyroid (Louis et al., 2014). These results find support in recent epidemiologic studies reporting an association between human urinary levels of certain UV filters and couples fecundity, i.e. BP-2 (Louis et al., 2014), and decrease semen quality, i.e. BP-3 
and BP-8. Therefore, (Louis et al., 2015) highlighted the importance of further studies exploring human exposure to UV filters. Despite the presence of UV filters has been reported in wastewater (Ramos et al., 2016; Tsui et al., 2014) no WBE approaches have been yet tested to evaluate human exposure to these substances. However, the high stability of these compounds and the indication of particular metabolite signatures (Le Fol et al., 2015) suggest potential biomarkers for UV filters in wastewater based biomarkers to support epidemiological studies (Table 1 and S2).

\subsection{Plasticizers}

Plastics are very versatile materials typically consisting of organic polymers of high molecular mass, which may contain other substances. Manufacturers often add different chemicals to plastics to give them specific characteristics, such as flexibility, resilience and pliability. These plasticizers mainly include phthalates and adipates, and because of their environmental persistence and their widespread use, it is unsurprising that they can be found in wastewater and in the receiving environment (Barnabé et al., 2008; Gao and Wen, 2016; Olofsson et al., 2013; Zolfaghari et al., 2014). Some of these chemicals and/or their derivatives interfere with endogenous hormone signalization in animals and humans, raising concerns about their potential to cause long-term diseases (Joint Fao Oms Expert Committee On Food Additives, 2010). In particular phthalates (e.g. bis(2-ethylhexyl) phthalate and, dibutyl phthalate) were associated with the disruption of hormonally-mediated pathways, as well as increased risk for cancer (“Toxicological profile for di(2-ethylhexyl)phthalate (DEHP)," 2002, “Toxicological profile for Di-n-butyl-Phthalate,” 2001). Furthermore, epidemiological observational studies suggest that there is a consistent association of blood and urine concentrations of phthalates, and some effects, such as those mentioned above (Joint Fao Oms Expert Committee On Food Additives, 2010; Kim et al., 2015; Wang et al., 2016). Due to a better toxicological profile (Bhat et al., 2014) and a better blood compatibility (Zhong et al., 2013), other plasticizers, such as di- 
isononyl cyclohexane-1,2-dicarboxylate $(\mathrm{DINCH})$, have been increasingly used in recent years as alternatives in PVC films and medical devices. Metabolites of phthalates, adipates, and DINCH have been found in urine (Fromme et al., 2016; Guo et al., 2011; Herrero et al., 2015; Loftus et al., 1993; Silva et al., 2007), but their presence in wastewater has never been investigated. For a list of known biomarkers in urine see Table S2.

\subsection{Flame retardants}

Flame retardants (FRs) are chemical additives for manufactured materials, such as plastics and textiles, to inhibit, suppress, or delay the production of flames to prevent the spread of fire. Brominated flame retardants (BFRs) and organophosphorus flame retardants (PFRs) are the most used classes of organic FRs. Due to their high $\log \mathrm{K}_{\mathrm{ow}}$, BFRs are lipophilic and preferentially retained in the human body, e.g. in the blood or adipose tissue. They are only slowly metabolized to hydroxylated metabolites (e.g. HO-PBDEs), which are also retained in the body and thus not excreted in the urine. The presence of BFRs in the sewer system is largely due to direct input from the indoor environment, following washing out of dust and being associated with particles. PFRs are less persistent and rapidly metabolized in the human body (Van den Eede et al., 2013), they have been measured in municipal wastewater in Europe (Loos et al., 2012; Marklund et al., 2005), Australia (O’Brien et al., 2014) and United States (Schreder and La Guardia, 2014). PFRs metabolites are excreted via urine and they are thus suitable biomarkers to assess human exposure to PFRs (Van den Eede et al., 2015); however, there are no reports on the presence of PFR metabolites in wastewater and no studies testing them in a WBE approach (Table S2).

\section{HEALTH BIOMARKERS}

Community health programs play an essential role for public health agencies to monitor and evaluate the present status of health in a community and measure the success of programs 
aimed at improving it. Current challenges mainly consist of the quick and reliable evaluation of the overall health of a population, and detect possible health and illness threats such as pandemics or higher prevalence of diabetes or cancer.

The quantitative measurement of specific exogenous and endogenous biomarkers related to these diseases in wastewater has the potential to provide rapid information on different factors related to public health and illness. Specific classes of pharmaceuticals such as antibiotics and benzodiazepines and their metabolites are exogenous compounds, which can be related to their use for specific illnesses or diseases, whereas endogenous compounds, such as $\alpha$-fetoprotein, chroriogonadotropin (hCG) and isoprostanes, are more directly related to cancer or stress.

In this section, both exogeneous and endogenous specific biomarkers are presented and suggested to monitor health issues (Table S3) through the WBE approach. In addition, DNAbased approaches, currently applied in the field of WBE, have been reviewed.

\subsection{Pharmaceuticals}

\subsubsection{Antibiotics}

Antibiotics (ABs) can be suitable biomarkers for representing human health status associated with bacterial infections. The determination of reliable data on their consumption is of interest as $\mathrm{AB}$ use is one of the main factors responsible for $\mathrm{AB}$ resistance (Euro-CDC, 2012). WBE may give a better understanding of real time use and misuse of ABs at the population level, by supporting for example prescription data from official sources and annual sales.

Many ABs are excreted unchanged in urine (Castiglioni et al., 2006; Huang et al., 2011), hence, parent drugs are generally targeted as biomarkers (Table S3). However, the selection of a significant $\mathrm{AB}$ biomarker should not be limited to the parent drug only; in fact, the investigation of specific metabolites is adding specificity to the analysis avoiding biases coming from the direct disposal of the AB. This is particularly relevant for ABs widely used for veterinary treatments. The most targeted classes of $\mathrm{ABs}$ are $\beta$-lactams, quinolones and fluoroquinolones, 
sulphonamides, tetracyclines and macrolides. Apart from $\beta$-lactams that undergo easy hydrolysis, sulphonamides and macrolides are very persistent, and are therefore also detected in treated wastewater (Jelic et al., 2012). Stability of the ABs metabolites in wastewater is less understood.

The occurrence of ABs in influent wastewater has been widely investigated in several countries (Gracia-Lor et al., 2012b; Kümmerer, 2009; Verlicchi et al., 2012). Seasonal variability of population-normalized mass loads was observed by Castiglioni et al. 2006, using the WBE approach, showing a difference in percentage from winter to summer of 47, 77 and 100 for ciprofloxacin, ofloxacin and sulphamethoxazole, respectively (Castiglioni et al., 2006). Temporal monitoring of ABs at several time scales showed a higher variability monthly/hourly than daily/weekly along with seasonality in mass fluxes for ciprofloxacin, ofloxacin and clindamycin (Coutu et al., 2013). Deconjugation during in-sewer transport may influence the influent loading of sulfamethoxazole (Snip et al., 2016) depending on the type and size of the served catchment (Polesel et al., 2016). Application of WBE helped in determining the usage of ABs in areas where consumption data were scarce or a proper regulation was missing, revealing an excessive use in China (Yuan et al., 2015).

\subsubsection{Benzodiazepines}

Benzodiazepines are used therapeutically for a considerable number of applications, including anxiety and sleep disorders. Their primary mode of action is an enhancement of the action of the neurotransmitter gamma-aminobutyric acid which may result in anticonvulsant, anxiolytic, hypnotic, muscle relaxant and sedative effects. Benzodiazepines and benzodiazepine analogs are commonly prescribed; however, they are also among the most frequently abused prescription medications (Button, 2015). Despite the risk for abuse, approximately $5.2 \%$ of US adults between 18 and 80 years of age used benzodiazepines in 2008, with a double prevalence for women than men (Olfson et al., 2015). As such, monitoring of benzodiazepines is of public concern. 
Monitoring benzodiazepines in populations could be achievable via WBE as they are normally halogenated and hence resistant to biodegradation (Kosjek et al., 2012). Multiple studies have already identified both parent benzodiazepines and their urinary metabolites in wastewater influent (Baker et al., 2014; Borova et al., 2014; Castrignanò et al., 2016; Fernández et al., 2014; Hummel et al., 2006; Kosjek et al., 2012; Racamonde et al., 2015, 2014). Differences in the behavior of benzodiazepines are associated with differences in functional substituent groups, and mainly the hydroxylated tranquilizers, oxazepam, and temazepam, were reported to be present in influent and effluent wastewater (Bijlsma et al., 2012; Hummel et al., 2006; Löffler et al., 2005).

A summary of the most commonly prescribed and detected benzodiazepine parent compounds and their metabolites, which have been identified in urine, in addition to identification in wastewater and stability data, when available, are presented in Table S3.

\subsubsection{Other pharmaceuticals}

Even if many works have analysed the presence of pharmaceuticals in urban wastewater, only a few studies investigated these chemicals as WBE biomarkers. Some examples can be found in Table 1. Furthermore, a list of proposed pharmaceuticals is given in Table S3 with their excretion rates.

\subsubsection{Chiral pharmaceuticals}

More than $50 \%$ of pharmaceuticals currently used are chiral although they are usually manufactured as racemic mixtures (Petrie et al., 2015; Vazquez-Roig et al., 2014). Human metabolism and microbial processes during wastewater treatment can result in the enrichment of one specific enantiomer. Thus, the analysis of chiral compounds in wastewater allows to distinguish between usage of pharmaceuticals due to intentional human ingestion and from accidental release (direct disposal). For instance, enantioselective analysis was used by (Vazquez-Roig et al., 2014) to 
tentatively propose direct disposal of atenolol where a moderate higher average daily load was observed. Recently, (Petrie et al., 2016) identified direct disposal of the antidepressant fluoxetine via the sewer network using wastewater analysis.

\subsection{Endogenous compounds}

Endogenous chemicals are produced by biological processes associated with stress or normal metabolism. Changes in biological mechanisms may result in alterations of the endogenous compound production and, therefore, measurement of such compounds can be used as indicator of health status and disease (Daughton, 2012b; Group, 2001; Hagger et al., 2006). Endogenous biomarker analysis has been extensively studied as diagnostic or prognostic tools in clinical medicine, and can be further applied to the field of WBE (Daughton, 2012b). Thus far, the investigation of endogenous biomarkers has been more focused on diseases such as cancer, diabetes and cardiovascular disorder than on the overall health status. However, the number of biomarkers validated for routine clinical practice is rather limited (Poste, 2011; Rifai et al., 2006), which falls into even smaller numbers of biomarkers for WBE when considering only those excreted into urine. Nevertheless, a range of endogenous compounds have been suggested as wastewater biomarkers of effect including cancer (prostate specific antigen, $\alpha$-fetoprotein) (Thomas and Reid, 2011; Yang et al., 2015c), oxidative stress (isoprostanes) (Daughton, 2012b; Ryu et al., 2015; Thomas and Reid, 2011) and health (anti-inflammatory eicosanoids) (Daughton, 2012b). To date, studies conducted on candidate endogenous biomarkers in wastewater are based on targeted analysis of specific markers such as isoprostanes (Ryu et al., 2015) and cancer biomarkers (Yang et al., 2015c). However, it is important to note that omics approaches also hold promising and important roles in future developments and applications of endogenous biomarkers analysis in WBE (Rice et al., 2015). The added value of analyzing these compounds would reside mainly in relative comparisons, both intraand inter- communities (Daughton, 2012b). Compared to the interpretation of the exogenous biomarkers, where absolute values are emphasized, the use of endogenous biomarkers is more 
focused on detecting changes over time or between communities. Such data can reveal emerging trends (i.e., early warning system) and health disparities caused by various factors (e.g., exposure, lifestyle).

\subsection{DNA}

The demand for sensitive, low-cost and high-throughput methods to characterize DNA/RNA sequences has driven the development of molecular biology techniques and bioinformatics, i.e., PCR-based approaches and next generation sequencing (NGS) (Ryoo et al., 2013). Massive sequencing is nowadays possible, owing to the development of different NGS platform that allows an entire genome to be sequenced in less than one week. These technical advances led to a rapid increase in new applications, including DNA-based health biomarkers. During the last decade an increasing number of studies took advantage of these developments, and applied them to the field of WBE. Several examples highlight the potential of the approach. In the field of virological surveillance, wastewater screening has been used to identify the viral strains that are circulating in the community, supporting epidemiological studies of the related viral infections and working as an early warning tool (Hellmér et al., 2014; Kokkinos et al., 2011; Mclellan et al., 2013; Zhou et al., 2014). Hellmér et al. 2014 investigated the presence of eight pathogenic viruses (norovirus, astrovirus, rotavirus, adenovirus, Aichi virus, parechovirus, hepatitis A virus [HAV], and hepatitis E virus) in wastewater from Sweden to explore whether their identification could be used as an early warning of outbreaks. Results show that two strains were involved in an ongoing outbreak in Scandinavia and were also identified in samples from patients with acute hepatitis A in Gothenburg during spring of 2013.

A similar framework has been applied in other areas such as the study of the epidemiology of the emerging human pathogens (Mclellan et al., 2013; Webb et al., 2015), and antibiotic resistance patterns of populations (Colomer-Lluch et al., 2014; Kumaraswamy et al., 2014; McLellan and Eren, 2014). One of the most recent applications has been in the field of 
human metabolic disorders. With the obesity epidemic reaching alarming levels, there is a need to set biomarkers to identify populations or sub-populations at risk (Lyssimachou et al., 2015). Recently, a good correlation has been established between the gut microbiome and obesity. In fact, only a few bacterial species are sufficient to distinguish between lean and obese individuals (Le Chatelier et al., 2013). These findings prompted a large study in the US using oligotyping of high-throughput 16S rRNA gene sequence data to screen wastewater from 71 cities. It was demonstrated that cities could be differentiated by their sewage bacterial communities, and the community structures were good predictors of a city's estimated level of obesity (Newton et al., 2015). This example illustrates that once specific biomarkers are identified, DNA-based analysis in wastewater can work as a powerful tool to support epidemiological studies

\section{POPULATION BIOMARKERS}

Accurate estimation of population size is necessary to normalize WBE data to the per capita level, which allows for temporal and spatial comparisons to be made (van Nuijs et al., 2011b). A review of all uncertainties associated with WBE found that there is a direct relationship between the uncertainty in measuring the population size and the uncertainty in the calculated daily loads of drugs (Castiglioni et al., 2013; Lai et al., 2015a). Therefore, accurate data on population size are needed to make decisions involved with planning and forecasting, assessing services and infrastructure, policy making, informing legislation and resource allocation at the level of neighborhood, city, province or country.

Current methodologies to estimate population size are based on public surveys (such as census taking), complemented with a wide array of demographic statistics, such as tourism and potential commuters. Census, however, can become increasingly outdated and cannot be easily updated to accommodate change such as births, deaths, and migration (movement). Ideally, the census should be able to estimate both the de jure and the de facto population. The de jure population comprises all "usual" residents, mainly those with formal residences. The de facto 
population comprises all those who are present, regardless of the location of their formal or usual residence (Daughton, 2012a). A de facto population therefore includes all non-residents (e.g., commuters, visitors, tourists) and excludes all permanent residents who are absent. However, the census approach acquires a static snapshot estimate and usually succeeds in only capturing a portion of the population. Population size can also be estimated from hydrochemical parameters that are routinely determined in the WWTPs, including chemical oxygen demand (COD), biological oxygen demand (BOD) and total nitrogen and phosphorus. However, these parameters are highly influenced by wastewater composition (i.e. industrial, domestic or mixed).

Addressing the population uncertainty and identifying suitable markers for the population size markers is thus an important aspect of WBE (Been et al., 2014; Brewer et al., 2012; Lai et al., 2011; O’Brien et al., 2014). Many compounds can be considered as biomarkers for population size. Possible candidates are both naturally occurring and synthetic xenobiotics (and their metabolites or formulation impurities), as well as products of endogenous metabolism. A variety of chemicals have been studied as biomarkers of population, including drugs (e.g., carbamazepine (Gasser et al., 2010)), biocides (e.g., triclosan (Singh et al., 2010)), chemicals in household cleaning agents, e.g., fluorescent whiteners, trialkylamines (Managaki et al., 2006; Valls et al., 1989), and food additives, e.g., sucralose (Oppenheimer et al., 2011). An essential characteristic for a biomarker to be useful for measuring population size is, in addition to the general requirements for a biomarker, to have a low variance in the per capita daily excretion (Daughton, 2012a); the knowledge of quantities excreted daily ensures that diurnal variations (e.g., resulting from circadian biorhythms) are fully accommodated. Another requisite for these groups of biomarkers is that daily per capita excretion should not be affected by variables such as season, weather and geographic location.

To date, none of the population size markers proposed have yet met all necessary criteria mentioned above and additional characteristics described before for a WBE biomarker should also be considered. Some specific applications are listed below. 


\subsection{Artificial sweeteners}

The most popular artificial sweeteners used in foodstuffs include acesulfame (ACE), alitame (ALI), aspartame (ASP), cyclamate (CYC), neotame (NEO), neohesperidin dihydrochalcone (NHDC), saccharin (SAC) and sucralose (SUC) (Table S4) (Kokotou et al., 2012; Lange et al., 2012). All of them, except NEO and ALI, are allowed to be used as additives in food by the European Union (EPCD, 2003), whereas five of them, ACE, ASP, NEO, SAC and SUC are approved to be used in the United States (USFDA, 2006).

After ingestion, ACE, CYC and SAC are unaffected by the human metabolism, and thus largely eliminated from human bodies mainly unchanged in urine (Fermin and Vallvey, 2004; Lange et al., 2012; Renwick, 1985; Roberts et al., 2000; Sardesai and Waldshan, 1991). Studies have shown that, due to variations in individual metabolism, CYC could be metabolized to cyclohexylamine and excreted in urine (Renwick et al., 2004). For ALI, 7-22\% is excreted unchanged in feces, while the rest, about $78-93 \%$ is hydrolyzed to aspartic acid and alanine amide (Fermin and Vallvey, 2004). The glucuronide conjugates of ALI metabolites are the major urinary metabolites in the first 24 hours. ASP is largely broken down in human gut to aspartic acid, phenylalanine and methanol (Fermin and Vallvey, 2004; Lange et al., 2012). NEO and its metabolites are excreted in urine and feces (WHO Food Additive Series No. 52, 2004). Less than $2 \%$ is excreted unchanged, but it is extensively metabolized in humans via de-esterification to $N$ [N-(3,3-dimethylbutyl)-L-alpha-aspartyl]-L-phenylalanine (WHO Food Additive Series No. 52, 2004). Minor metabolites of NEO include $N$-(3,3-dimethylbutyl)-L-aspartic acid, 3,3dimethylbutanoic acid and the carnitine conjugate and glucuronide conjugate of 3,3dimethylbutanoic acid (WHO Food Additive Series No. 52, 2004). NHDC is hydrolyzed in humans to isoferulic acid, 3-hydroxyphenylpropionic acid, and 3-hydroxycinnamic acid (Fermin and Vallvey, 2004; Lange et al., 2012). SUC is mainly excreted unchanged in human feces, 
while $8-22 \%$ was excreted in urine unchanged together with its glucuronide conjugates (Roberts et al., 2000).

ACE, CYC, SAC, and SUC were found highly stable in raw wastewater at $4^{\circ} \mathrm{C}$ and room temperature over four days (Ordóñez et al., 2012). Under these conditions, only 20-30\% of ASP remained after one day and none left after two days. Similarly, the amount of NHDC was found less than $10 \%$ in the raw wastewater at $4{ }^{\circ} \mathrm{C}$ after one day and linearly decreased at room temperature over three days. Similar results were also reported in another study, in which ACE, CYC, SAC and SUC remained stable in raw wastewater at $4^{\circ} \mathrm{C}$ over three weeks, whereas ASP and NHDC were degraded within a day (Tran et al., 2013).

Since they are exclusively non-metabolized in humans and highly stable in wastewater, the parent compounds ACE, CYC, SAC and SUC can be measured for the WBE approach. However, the analysis of the metabolites of ALI, ASP, NEO and NHDC, rather than of the parent compounds, is required, since these artificial sweeteners are largely metabolized in humans. Stability tests for the metabolites in raw wastewater are also necessary for future studies. The use of artificial sweeteners has been shown to be highly related to human activities (Buerge et al., 2009) and, therefore, human consumption is considered as the major source of these substances in raw wastewater; however, other sources, such as animal feedings, agriculture farms and industries, can contribute to their presence in sewage systems (Kokotou et al., 2012).

Certain artificial sweeteners also showed a specific weekly pattern: in general higher loads in influents (i.e. consumption) were observed during weekdays than during weekends (Kokotou et al., 2013). This could be associated with more commuters during the weekday than the weekend in the studied catchment. These previous studies together suggested that measuring artificial sweeteners could be useful for the WBE approach to understand the population flow in a given catchment. This concept of using human consumed chemicals, such as the artificial sweetener ACE, to back-estimate the population size from a given wastewater sample was firstly attempted and discussed by (Lai et al., 2011) and further refined using wastewater samples 
collected on the census day and applying a Bayesian model (O'Brien et al., 2014). Importantly, with chemical-derived population estimates, the robustness of the WBE data was improved, since the total methodological uncertainty of the approach was reduced (Lai et al., 2015a, 2011).

\subsection{Nicotine}

Currently, nicotine and its metabolites have been used as population markers on two occasions (Chen et al., 2014; Senta et al., 2015a). In the first case, the authors focused solely on cotinine, whose loads varied only limitedly over one week and showed good correlation with the size of the investigated populations (i.e., correlation coefficient $=0.981)($ Chen et al., 2014). However, geographical/cultural differences in tobacco use or fluctuations in the number of users have been raised as potential flaws to the use of cotinine as population marker (Chen et al., 2014). Moreover, consumption of tobacco could change due to tax and other tobacco-related policies, which could affect the potential of nicotine and its metabolites as population markers. In the second study (Senta et al., 2015a), cotinine and trans-3'-hydroxycotinine loads were used to estimate the number of individuals contributing to the collected wastewater samples. Good agreement was found between nicotine metabolite load population estimates and census data, suggesting that the method is a viable approach to estimate the size of a population.

\subsection{Caffeine}

Caffeine and some of its major metabolites were recently tested as a population biomarkers. Caffeine was one of the compounds included in the exploratory study to estimate population size using samples collected on the census day and applying a Bayesian model (O’Brien et al., 2014). A strong correlation between caffeine mass loads and population size was observed. In the second study, generally good agreement between caffeine loads and hydrochemical parameters routinely determined at the WWTPs was found (Rico et al., 2016). In 
another recent study, three major caffeine metabolites: 1-methylxanthine, 7-methylxanthine and paraxanthine were tested together with caffeine as possible population biomarkers (Senta et al., 2015a). These compounds fulfilled some of the major requirements for an ideal biomarker - they are easily detectable and stable in wastewater samples. However, their mass loads in wastewater did not completely reflect the human excretion profile of caffeine, probably due to biases in caffeine pharmacokinetic data (see section 2.4 and Table S2) and additional sources of some metabolites and unconsumed caffeine. This makes the possibility of using caffeine and/or its metabolites as biomarkers for population size assessment rather difficult, at least without additional studies.

\subsection{Pharmaceuticals}

Concentrations and mass loads of pharmaceuticals in wastewater were used in the WBE field for the estimation of population size only on three occasions (Lai et al., 2011; O'Brien et al., 2014; Rico et al., 2016). The investigated compounds by Lai et al. (Lai et al., 2011) were atenolol (beta-blocker), gabapentin (anti-convulsant), hydrochlorothiazide (diuretic), and venlafaxine (anti-depressant). Atenolol was concluded to be the best option for this aim for the specific catchment. In addition to the compounds selected by Lai et al., the same group also investigated carbamazepine (antiepileptic), codeine, ibuprofen, paracetamol (analgesics), furosemide (diuretic), iopromide (contrast medium), naproxen (anti-inflammatory) and salicylic acid (metabolite of acetylsalicylic acid) and the measured loads were used in a collective model for the estimation of the population size (O'Brien et al., 2014). By cross validating the data, the authors demonstrated that large populations sizes could be estimated fairly accurately using the information of multiple chemical mass loads. However, it could not be improved for small populations. In the work published by (Rico et al., 2016) twelve human urine biomarkers were tested to estimate population size, six of them being pharmaceuticals (hydrochlorothiazide, carbamazepine, codeine, naproxen, salicylic acid and atenolol). However, by using these 
compounds, the population was under or overestimated compared to the hydrochemical population, but they have good prospects if the appropriate data sales are available.

\subsection{Endogenous compounds}

An alternative for estimating the population size in the catchment area of a WWTP relies on monitoring influent wastewater for a biomarker linked to human metabolism. Chemicals involved in endogenous metabolism avoid many of the problems encountered with xenobiotics, since their association with human activities has a higher fidelity. Yet, their main problem is excessive intra- and inter-individual variation in excretion. Biomarkers of endogenous origin derive from human biochemical processes and undergo continuous urinary or fecal excretion. Several endogenous biomarkers, which have been considered in the past or which have the potential to estimate the population size more accurately (Table S4), are further discussed.

An important endogenous biomarker, widely used in clinical chemistry and with detailed knowledge about its excretion, is creatinine (CR). A small portion of creatine (and phosphocreatine), which is stored predominately in skeletal muscle, is continually converted to form the endogenous anhydride, CR (a nitrogenous waste product cleared via the kidney); the rate of conversion, in males for example, is about $1.6-1.7 \%$ per day. The major factors involved with variability in CR output have been summarized by (Ryan et al., 2011). However, intra- and inter-day CR excretion is not constant and daily excreted quantities can have high variance, being strongly influenced by diet composition. In addition, $\mathrm{CR}$ is being increasingly used as a food and nutritional supplement, adding yet another source of potential variation to CR excretion rates. Although CR has been used in WBE studies as population marker (Brewer et al., 2012; Chiaia et al., 2008), it was shown to be unstable in wastewater (completely decomposed within 24 h)_(Chen et al., 2014).

Another potential biomarker is coprostanol $(\mathrm{CoP})$ that originates from gut microbial metabolism, making up roughly $60 \%$ of the overall sterol content in human feces. CoP is poorly 
absorbed from the gut (it does not undergo enterohepatic circulation) and is therefore fully excreted in the feces. Since the 2000s, CoP has been used as anthropogenic marker in wastewater and to gauge the degree of dilution of raw or treated wastewater in receiving surface water (Takada and Eganhouse, 1998). However, CoP is excreted by various vertebrates in differing absolute and relative quantities and it is sometimes difficult to distinguish between human and animal contamination (Bull et al., 2002). Furthermore, CoP adsorbs substantially onto particulate matter found in wastewater and was thus discarded as potential population marker (Chen et al., 2014). Similar results were obtained for cholesterol (Chen et al., 2014); cortisol and androstenedione were investigated, but rapidly degraded in wastewater (Chen et al., 2014).

Another example of biomarker relatively unique to human metabolism is 1-aminopropan2-one (1-aminopropanone: APR; 1-aminoketone). Through 1-aminopropan-2-ol, APR serves as a precursor to vitamin B-12 (Fitzsimons and Belt, 2005). It is very water soluble and it is excreted via urine, but in much lower daily quantities than CoP. However, it is sometimes found in wastewater at levels higher than in urine, implicating potential de novo microbial formation in sewage (Fitzsimons and Belt, 2005), whilst it could not be detected on other occasions (Singh and Gardinali, 2006).

5-hydroxyindoleacetic acid (5-HIAA), a metabolite of serotonin, has also been investigated. Its excretion might be altered due to diseases (e.g., carcinoid tumors (Zuetenhorst, 2004)) and diet (i.e., some fruits and nuts (Feldman and Lee, 1985) and salt intake (Sharma et al., 1993). Furthermore, intra- and inter-individual variability in excretion has also been highlighted (Curtin et al., 1996). Results from wastewater analysis showed good correlation with census data and the authors considered it as a promising marker (Chen et al., 2014).

Ammonium $\left(\mathrm{NH}_{4}^{+}\right)$represents the major form in which ammonia $\left(\mathrm{NH}_{3}\right)$ is found in wastewater and originates from the breakdown of urea (Udert et al., 2006). It is mainly introduced via toilets (Butler et al., 1995) and it is routinely measured by WWTP as a water quality parameter. It is supposedly less affected by non-human sources compared to conventional 
parameters (e.g., chemical or biological oxygen demand, total phosphorous) (van Nuijs et al., 2011b) and can potentially be measured online using ion-selective electrodes. Fluctuations in ammonium loads have been shown to link well to population dynamics (Been et al., 2014). Yet, its use to estimate absolute figures of the size of the de facto population might be undermined in rural areas due to the contribution of agricultural sources.

\subsection{DNA}

Deoxyribonucleic acid (DNA) is a nucleic acid that carries most of the genetic instructions from all known living organisms and many viruses. DNA can be naturally shed into the environment through urine, feces, exudates or tissue residues. Compared to most of chemical compounds as a candidate of population biomarkers, DNA is much more stable and able to persist in the environment from month to hundred years depending on species (Prüfer et al., 2014; Thomsen and Willerslev, 2015). DNA biomarkers have been widely used in the field of medical diagnostics and biomedicine (Altintas and Tothill, 2013; Liu et al., 2011; Ralla et al., 2014; Wang et al., 2012). For WBE, DNA has a great potential to act as a population biomarker, not only because of its little affinity to other species in wastewater and constant excretion by humans, but also for its extreme stability and the possibility of being quantifiable Those robotic characteristics well meet the proposed criteria of a proper population biomarker candidate (Dejean et al., 2011; Thomsen and Willerslev, 2015).

Typically, the changes of DNA component and structure such as DNA damage, repair and mutation could be used as biomarkers. Recently, a H2AX histone phosphorylation assay was developed as DNA damage biomarker for human population study, as it represents an early event in the cellular response against DNA double-strand breaks (Sánchez-Flores et al., 2015). However, to select a population biomarker for WBE uses, one of the crucial criteria is to screen human specific DNA. Wastewater is a complex matrix, which may contain DNA from various species such as plants, animals, and viruses. A recent study by Yang et al (Yang et al., 2015a, 
2015b) has proposed to use community sewage sensors to identify human-specific mitochondrial DNA as a potential population biomarkers. In this study, human specific mitochondrial DNA associated with disease biomarkers (Liu et al., 2011; Tipirisetti et al., 2014) was amplified from wastewater by a specifically designed primer using quantitative real-time polymerase chain reaction (PCR) (Yang et al., 2015a). More importantly, the amplicons were detectable by an electrochemical biosensor based on a custom synthesized ferrocence intercalator as a signal transducer. The developed biosensors allow for the detection of single nucleotide variation and enable the potential of portable sensors for rapid identification of specific human biomarkers in wastewater. 


\section{CONCLUSIONS AND FUTURE PERSPECTIVES}

WBE is a rapidly developing scientific discipline with a strong transdisciplinary character. It has shown great progress, and opens up many possibilities for expanding its application to provide relevant information about lifestyle and public health.

This review has outlined potential wastewater biomarkers of exposure or effect that could be used for future applications associated with lifestyle and wellbeing studies. However, it has also discussed limitations and highlighted that more research is needed, for various proposed biomarkers, before WBE can appropriately be applied. Moreover, several trends, needs and recommendations are indicated:

- Human pharmacokinetic data (metabolism and urinary profile of excretion) are necessary to ensure that the candidate biomarker is formed in the body in a high proportion and is excreted mainly via urine. This information is highly relevant not only to back-calculate the consumption/exposure of a certain substance by a community, but also to distinguish the amount of a substance coming from human or other sources.

- In-sample and in-sewer stability studies are needed for a better application in WBE. Stability tests are often performed in the laboratory, trying to reproduce the real conditions of temperature and sewage composition or in-sewer conditions. An alternative would be the use of in-silico tools to predict the stability of a compound in wastewater treatment processes. These models do not guarantee the formation of a biotransformation product, so it may be used as an indicator or a guide about the in-sewer stability of a residue and its potential adsorption (Reid 2014). Sorption onto the solid particulate or the conjugation of the biomarkers must also be taken into account when assessing stability.

- Source identification is needed to ensure that discharges from exogenous sources that might cause overestimation of the real amounts consumed are considered.

- Cross validation of data (e.g. concentrations of pharmaceuticals in wastewater with bench-top sales) is recommended for all applications. 
- Multiple biomarkers for estimating the population size need to be set to allow for the normalization of the data. The development of portable biosensors may allow rapid estimation of the population contributing to the wastewater samples in the near future.

- Regular monitoring of sewage for viruses based on similar DNA biosensors may give an early warning of a possible upcoming outbreak.

- Omics approaches also hold promising and important roles in future developments and applications of endogenous biomarkers analysis in WBE. 


\section{ACKNOWLEDGEMENTS}

This work was supported by the COST Action ES1307 "SCORE - Sewage biomarker analysis for community health assessment”. Emma Gracia-Lor is very grateful to Generalitat Valenciana, Conselleria d'Educació, Investigació, Cultura i Esport (APOSTD/2015, Programa $\mathrm{VALi}+\mathrm{d}$ ) for her post-doctoral contract. Lubertus Bijlsma acknowledges NPS-Euronet (HOME/2014/JDRUG/AG/DRUG/7086), co-funded by the European Union, for his postdoctoral fellowship. Erika Castrignanò, Richard Bade, Juliet Kinyua, Pedram Ramin, Nikolaos I. Rousis, Yeonsuk Ryu would like to thank the SEWPROF MC ITN project, 'A new paradigm in drug use and human health risk assessment: Sewage profiling at the community level' [grant agreement 317205] supported by the European Union's Seventh Framework Programme for research, technological development and demonstration for the financial support. Iria GonzálezMariño extends her gratitude to the Galician Council of Culture, Education and Universities for her postdoctoral contract (Plan Galego de Investigación, Innovación e Crecemento 2011-2015). Foon Yin Lai acknowledges her postdoctoral fellowship from the University of Antwerp. Luigi Lopardo, Axel Rydevik and Barbara Kasprzyk-Hordern would like to acknowledge Leverhulme Trust for funding 'TOX-EDC, Wastewater profiling for community-wide human exposure assessment from environmental endocrine disrupting chemicals in personal care and consumer products' (Project No: RPG-2013-297). Frederic Been would like to thank the Swiss National Science Foundation (SNF, P2LAP2_164892) for his post-doctoral grant. This publication reflects the views only of the authors, and the European Commission cannot be held responsible for any use which may be made of the information contained therein. 
Table 1. Overview of the most relevant biomarkers used so far and potential biomarkers (for more details, please read the corresponding text and/or supporting information).

\begin{tabular}{|c|c|c|c|c|}
\hline Class & Parent compound & $\begin{array}{c}\text { Biomarker/potential } \\
\text { biomarker }\end{array}$ & $\begin{array}{l}\text { WBE } \\
\text { applicatio } \\
\mathbf{n}\end{array}$ & Reference \\
\hline \multirow[t]{5}{*}{ Illicit drugs } & Cocaine & Benzoylecgonine & YES & $\begin{array}{l}\text { (Castiglioni and } \\
\text { Gracia-Lor, } \\
\text { 2015; Gracia- } \\
\text { Lor et al., } \\
\text { 2016) }\end{array}$ \\
\hline & Amphetamine & Amphetamine & YES & $\begin{array}{c}\text { (Castiglioni and } \\
\text { Gracia-Lor, } \\
\text { 2015; Gracia- } \\
\text { Lor et al., } \\
\text { 2016) }\end{array}$ \\
\hline & Methamphetamine & Methamphetamine & YES & $\begin{array}{c}\text { (Castiglioni and } \\
\text { Gracia-Lor, } \\
\text { 2015; Gracia- } \\
\text { Lor et al., } \\
\text { 2016) }\end{array}$ \\
\hline & MDMA & MDMA & YES & $\begin{array}{l}\text { (Castiglioni and } \\
\text { Gracia-Lor, } \\
\text { 2015; Gracia- } \\
\text { Lor et al., } \\
\text { 2016) }\end{array}$ \\
\hline & THC/Cannabis & THC-COOH & YES & $\begin{array}{l}\text { (Castiglioni and } \\
\text { Gracia-Lor, } \\
\text { 2015; Gracia- } \\
\text { Lor et al., } \\
\text { 2016) }\end{array}$ \\
\hline Alcohol & Ethanol & Ethyl sulfate & YES & $\begin{array}{c}\text { (Rodríguez- } \\
\text { Álvarez et } \\
\text { al., 2015) }\end{array}$ \\
\hline Tobacco & Nicotine & $\begin{array}{r}\text { Cotinine + trans-3'- } \\
\text { hydroxycotinine }\end{array}$ & YES & $\begin{array}{c}\text { (Castiglioni et } \\
\text { al., 2015b) }\end{array}$ \\
\hline Caffeine & Caffeine & See Table S1 & $\mathrm{NO}$ & \\
\hline NPS & & See Table S1 & $\mathrm{NO}$ & \\
\hline \multirow[t]{3}{*}{ Pesticides } & 20 pyrethroids & 3-PBA & YES & $\begin{array}{c}\text { (Rousis et al., } \\
2016 \mathrm{~b})\end{array}$ \\
\hline & $\begin{array}{l}\text { Permetrin, } \\
\text { cypermetrin, } \\
\text { cyflutrin } \\
\end{array}$ & cis-DCCA & YES & $\begin{array}{c}\text { (Rousis et al., } \\
2016 \mathrm{~b})\end{array}$ \\
\hline & $\begin{array}{l}\text { Permetrin, } \\
\text { cypermetrin, } \\
\text { cyflutrin } \\
\end{array}$ & trans-DCCA & YES & $\begin{array}{c}\text { (Rousis et al., } \\
2016 \mathrm{~b})\end{array}$ \\
\hline Mycotoxines & & See Table S2 & $\mathrm{NO}$ & \\
\hline Parabens & & See Table S2 & $\mathrm{NO}$ & \\
\hline
\end{tabular}




\begin{tabular}{|c|c|c|c|c|}
\hline UV-filters & & See Table S2 & NO & \\
\hline Plasticizers & & See Table S2 & $\mathrm{NO}$ & \\
\hline $\begin{array}{l}\text { Flame } \\
\text { retardants }\end{array}$ & & See Table S2 & NO & \\
\hline \multirow[t]{6}{*}{ Pharmaceuticals } & Atenolol & Atenolol & YES & $\begin{array}{c}\text { (Baz-Lomba et } \\
\text { al., 2016; van } \\
\text { Nuijs et al., } \\
\text { 2015) }\end{array}$ \\
\hline & Citalopram & Citalopram & YES & $\begin{array}{c}\text { (Baz-Lomba et } \\
\text { al., 2016; van } \\
\text { Nuijs et al., } \\
\text { 2015) }\end{array}$ \\
\hline & Carbamazepine & Carbamazepine & YES & $\begin{array}{c}\text { (Baz-Lomba et } \\
\text { al., 2016; van } \\
\text { Nuijs et al., } \\
\text { 2015) }\end{array}$ \\
\hline & Diclofenac & Diclofenac & YES & $\begin{array}{c}\text { (Baz-Lomba et } \\
\text { al., 2016) }\end{array}$ \\
\hline & Metformin & Metformin & YES & $\begin{array}{c}\text { (van Nuijs et al., } \\
2015)\end{array}$ \\
\hline & Valsartan & Valsartan & YES & $\begin{array}{c}\text { (van Nuijs et al., } \\
2015)\end{array}$ \\
\hline Benzodiazepines & Oxazepam & Oxazepam & YES & $\begin{array}{c}\text { (Baz-Lomba et } \\
\text { al., 2016) }\end{array}$ \\
\hline $\begin{array}{l}\text { Artificial } \\
\text { sweeteners }\end{array}$ & Acesulfame & Acesulfame & YES & $\begin{array}{r}\text { (Lai et al., } \\
2015 a)\end{array}$ \\
\hline \multirow{2}{*}{$\begin{array}{l}\text { Endogenous } \\
\text { Compounds }\end{array}$} & Serotonin & 5-HIAA & YES & $\begin{array}{c}\text { (Rico et al., } \\
2016)\end{array}$ \\
\hline & Ammonia & Ammonium & YES & $\begin{array}{c}\text { (Been et al., } \\
2014)\end{array}$ \\
\hline
\end{tabular}




\section{REFERENCES}

Altintas, Z., Tothill, I., 2013. Biomarkers and biosensors for the early diagnosis of lung cancer. Sensors Actuators B Chem. 188, 988-998. doi:10.1016/j.snb.2013.07.078

Andrés-Costa, M.J., Escrivá, Ú., Andreu, V., Picó, Y., 2016. Estimation of alcohol consumption during "Fallas" festivity in the wastewater of Valencia city (Spain) using ethyl sulfate as a biomarker. Sci. Total Environ. 541, 616-622. doi:10.1016/j.scitotenv.2015.09.126

Anfossi, L., Giovannoli, C., Baggiani, C., 2016. Mycotoxin detection. Curr. Opin. Biotechnol. 37, 120-126. doi:10.1016/j.copbio.2015.11.005

Asimakopoulos, A., Kannan, K., 2016. Neuropsychiatric pharmaceuticals and illicit drugs in wastewater treatment plants: A review. Environ. Chem. doi:http://dx.doi.org/10.1071/EN15202

Bade, R., Bijlsma, L., Sancho, J. V., Baz-Lomba, J.A., Castiglioni, S., Castrignanò, E., Causanilles, A., Gracia-Lor, E., Kasprzyk-Hordern, B., Kinyua, J., McCall, A.-K., van Nuijs, A.L.N., Ort, C., Plósz, B.G., Ramin, P., Rousis, N.I., Ryu, Y., Thomas, K. V., Voogt, P. de, Zuccato, E., Hernández, F., 2016. Liquid chromatography-tandem mass spectrometry determination of synthetic cathinones and phenethylamines in influent wastewater of eight European cities. Chemosphere. doi:http://dx.doi.org/10.1016/j.chemosphere.2016.10.107

Baker, D.R., Barron, L., Kasprzyk-Hordern, B., 2014. Illicit and pharmaceutical drug consumption estimated via wastewater analysis. Part A: Chemical analysis and drug use estimates. Sci. Total Environ. 487, 629-641. doi:10.1016/j.scitotenv.2013.11.107

Baker, D.R., Kasprzyk-Hordern, B., 2011. Critical evaluation of methodology commonly used in sample collection, storage and preparation for the analysis of pharmaceuticals and illicit drugs in surface water and wastewater by solid phase extraction and liquid chromatography-mass spectrometry. J. Chromatogr. A 1218, 8036-8059. doi:10.1016/j.chroma.2011.09.012

Barnabé, S., Beauchesne, I., Cooper, D.G., Nicell, J.A., 2008. Plasticizers and their degradation products in the process streams of a large urban physicochemical sewage treatment plant. Water Res. 42, 153-162. doi:10.1016/j.watres.2007.07.043

Barr, D.B., 2008. Biomonitoring of exposure to pesticides. J. Chem. Heal. Saf. 15, 20-29. doi:10.1016/j.jchas.2008.07.001

Baselt, R.C., 2004. Disposition of toxic drugs and chemicals in man., 7th ed. Biochemical Publications (California, USA).

Baz-Lomba, J.A., Salvatore, S., Gracia-Lor, E., Bade, R., Castiglioni, S., Castrignanò, E., Causanilles, A., Hernandez, F., Kasprzyk-Hordern, B., Kinyua, J., McCall, A.-K., van Nuijs, A., Ort, C., Plósz, B.G., Ramin, P., Reid, M., Rousis, N.I., Ryu, Y., de Voogt, P., Bramness, J., Thomas, K., 2016. Comparison of pharmaceutical, illicit drug, alcohol, nicotine and caffeine levels in wastewater with sale, seizure and consumption data for 8 European cities. BMC Public Health 16, 1035. doi:10.1186/s12889-016-3686-5

Been, F., Benaglia, L., Lucia, S., Gervasoni, J.P., Esseiva, P., Delémont, O., 2015. Data triangulation in the context of opioids monitoring via wastewater analyses. Drug Alcohol Depend. 151, 203-210. doi:10.1016/j.drugalcdep.2015.03.022

Been, F., Rossi, L., Ort, C., Rudaz, S., Delémont, O., Esseiva, P., 2014. Population normalization with ammonium in wastewater-based epidemiology: Application to illicit drug monitoring. Environ. Sci. Technol. 48, 8162-8169. doi:10.1021/es5008388

Bencharit, S., Morton, C.L., Xue, Y., Potter, P.M., Redinbo, M.R., 2003. Structural basis of heroin and cocaine metabolism by a promiscuous human drug-processing enzyme. Nat. Struct. Biol. 10, 349-356. doi:10.1038/nsb919

Benowitz, N.L., Jacob, P., 1994. Metabolism of nicotine to cotinine studied by a dual stable isotope method. Clin. Pharmacol. Ther. 56, 483-493. doi:10.1038/clpt.1994.169

Bhat, V.S., Durham, J.L., Ball, G.L., English, J.C., 2014. Derivation of an Oral Reference Dose (RfD) for the Nonphthalate Alternative Plasticizer 1,2-Cyclohexane Dicarboxylic Acid, Di- 
Isononyl Ester (DINCH). J. Toxicol. Environ. Health. B. Crit. Rev. 17, 63-94. doi:10.1080/10937404.2013.876288

Bijlsma, L., Beltran, E., Boix, C., Sancho, J. V., Hernández, F., 2014. Improvements in analytical methodology for the determination of frequently consumed illicit drugs in urban wastewater. Anal. Bioanal. Chem. 406, 4261-4272. doi:10.1007/s00216-014-7818-4

Bijlsma, L., Emke, E., Hernandez, F., de Voogt, P., 2012. Investigation of drugs of abuse and relevant metabolites in Dutch sewage water by liquid chromatography coupled to high resolution mass spectrometry. Chemosphere 89, 1399-1406. doi:10.1016/j.chemosphere.2012.05.110

Bijlsma, L., Miserez, B., Ibáñez, M., Vicent, C., Guillamón, E., Ramsey, J., Hernández, F., 2016. Identification and characterization of a novel cathinone derivative 1-(2,3-dihydro-1H-inden-5yl)-2-phenyl-2-(pyrrolidin-1-yl)-ethanone seized by customs in Jersey. Forensic Toxicol. 34, 144-150. doi:10.1007/s11419-015-0299-0

Bisceglia, K.J., Lippa, K.A., 2014. Stability of cocaine and its metabolites in municipal wastewater - the case for using metabolite consolidation to monitor cocaine utilization. Environ. Sci. Pollut. Res. 21, 4453-4460. doi:10.1007/s11356-013-2403-5

Blanchard, J., Sawers, S., Jonkman, J., Tang-Liu, D., 1985. Comparison of the urinary metabolite profile of caffeine in young and elderly males. Br. J. Clin. Pharmacol. 19, 225-232. doi:10.1111/j.1365-2125.1985.tb02635.x

Błędzka, D., Gromadzińska, J., Wąsowicz, W., 2014. Parabens. From environmental studies to human health. Environ. Int. 67, 27-42. doi:10.1016/j.envint.2014.02.007

Boogaerts, T., Covaci, A., Kinyua, J., Neels, H., van Nuijs, A., 2016. Spatial and temporal trends in alcohol consumption in Belgian cities: a wastewater-based approach. Drug Alcohol Depend. 160, 170-176. doi:10.1016/j.drugalcdep.2016.01.002

Borova, V.L., Gago-Ferrero, P., Pistos, C., Thomaidis, N.S., 2015. Multi-residue determination of 10 selected new psychoactive substances in wastewater samples by liquid chromatographytandem mass spectrometry. Talanta 144, 592-603. doi:10.1016/j.talanta.2015.06.080

Borova, V.L., Maragou, N.C., Gago-Ferrero, P., Pistos, C., Thomaidis, N.S., 2014. Highly sensitive determination of 68 psychoactive pharmaceuticals, illicit drugs, and related human metabolites in wastewater by liquid chromatography-tandem mass spectrometry. Anal. Bioanal. Chem. 406, 4273-4285. doi:10.1007/s00216-014-7819-3

Brausch, J.M., Rand, G.M., 2011. A review of personal care products in the aquatic environment: Environmental concentrations and toxicity. Chemosphere 82, 1518-1532. doi:10.1016/j.chemosphere.2010.11.018

Brewer, A.J., Ort, C., Banta-green, C.J., Berset, J., Field, J. a, 2012. Normalized diurnal and between-day trends in illicit and legal drug loads that account for changes in the population. Environ. Sci. Technol. 46, 8305-8314. doi:dx.doi.org/10.1021/es202447r |

Buerge, I.J., Buser, H.-R., Kahle, M., Müller, M.D., Poige, T., 2009. Ubiquitous occurrence of the artificial sweetener acesulfame in the aquatic environment: An ideal chemical marker of domestic wastewater in groundwater. Environ. Sci. Technol. 43, 4381-4385.

Buerge, I.J., Kahle, M., Buser, H.-R., Müller, M.D., Poiger, T., 2008. Nicotine Derivatives in Wastewater and Surface Waters: Application as Chemical Markers for Domestic Wastewater. Environ. Sci. Technol. 42, 6354-6360. doi:10.1021/es800455q

Buerge, I.J., Poiger, T., Müller, M., Buser, H., 2003. Caffeine, an anthropogenic marker for wastewater comtamination of surface waters. Environ. Sci. Technol. 37, 291-300.

Bull, I.D., Lockheart, M.J., Elhmmali, M.M., Roberts, D.J., Evershed, R.P., 2002. The origin of faeces by means of biomarker detection. Environ. Int. 27, 647-654. doi:10.1016/S01604120(01)00124-6

Butler, D., Friedler, E., Gatt, K., 1995. Characterising the quantity and quality of domestic wastewater inflows. Water Sci. Technol. 31, 13-24.

Button, J., 2015. New Psychoactive Substances: the benzodiazepine boom. TIAFT Bull. June 2015. 
Bye, C., Munro-Faure, A.D., Peck, A.W., Young, P.A., 1973. A comparison of the effects of 1benzylpiperazine and dexamphetamine on human performance tests. Eur. J. Clin. Pharmacol. 6, 163-169. doi:10.1007/BF00558280

Byrd, G.D., Chang, K.M., Greene, J.M., 1992. Evidence for urinary excretion of glucuronide conjugates of nicotine, cotinine, and trans-3'-hydroxycotinine in smokers. Drug Metab. Dispos. 20, 192-197.

Callahan, M.M., Robertson, R.S., Branfman, a. R., McComish, M.F., Yesair, D.W., 1983. Comparison of caffeine metabolism in three nonsmoking populations after oral administration of radiolabeled caffeine. Drug Metab. Dispos. 11, 211-217.

Carrillo, J.A., Benitez, J., 1994. Caffeine metabolism in a healthy Spanish population: N-Acetylator phenotype and oxidation pathways. Clin. Pharmacol. Ther. 293-304.

Castiglioni, S., Bagnati, R., Fanelli, R., Pomati, F., Calamari, D., Zuccato, E., 2006. Removal of pharmaceuticals in sewage treatment plants in Italy. Environ. Sci. Technol. 40, 357-363. doi:10.1021/es050991m

Castiglioni, S., Bagnati, R., Melis, M., Panawennage, D., Chiarelli, P., Fanelli, R., Zuccato, E., 2011a. Identification of cocaine and its metabolites in urban wastewater and comparison with the human excretion profile in urine. Water Res. 45, 5141-5150. doi:10.1016/j.watres.2011.07.017

Castiglioni, S., Bijlsma, L., Covaci, A., Emke, E., Hernández, F., Reid, M., Ort, C., Thomas, K. V., Van Nuijs, A.L.N., De Voogt, P., Zuccato, E., 2013. Evaluation of uncertainties associated with the determination of community drug use through the measurement of sewage drug biomarkers. Environ. Sci. Technol. 47, 1452-1460. doi:10.1021/es302722f

Castiglioni, S., Borsotti, A., Senta, I., Zuccato, E., 2015a. Wastewater analysis to monitor spatial and temporal patterns of use of two synthetic recreational drugs, Ketamine and Mephedrone, in Italy. Environ. Sci. Technol. 49, 5563-5570. doi:10.1021/es5060429

Castiglioni, S., Gracia-Lor, E., 2015. Chapter 3. Wastewater drug target residues. European Monitoring Centre for Drugs and Drug Addiction, EMCDDA, in: European Monitoring Centre for Drugs and Drug Addiction, EMCDDA. Insight 9 Update.

Castiglioni, S., Senta, I., Borsotti, A., Davoli, E., Zuccato, E., 2015b. A novel approach for monitoring tobacco use in local communities by wastewater analysis. Tob. Control 24, 38-42. doi:10.1136/tobaccocontrol-2014-051553

Castiglioni, S., Zuccato, E., Chiabrando, C., Fanelli, R., Bagnati, 2008. Mass spectrometric analysis of illicit drugs in wastewater and surface water. Mass Spectrom. Rev. 27, 378-394. doi:10.1002/mas

Castiglioni, S., Zuccato, E., Fanelli, R., 2011b. Illicit Drugs in the Environment: Occurrence, Analysis, and Fate Using Mass Spectrometry. Wiley. doi:10.1007/978-1-60761-527-9

Castrignanò, E., Lubben, A., Kasprzyk-Hordern, B., 2016. Enantiomeric profiling of chiral drug biomarkers in wastewater with the usage of chiral liquid chromatography coupled with tandem mass spectrometry. J. Chromatogr. A 1438, 84-99. doi:10.1016/j.chroma.2016.02.015

Chen, C., Kostakis, C., Gerber, J.P., Tscharke, B.J., Irvine, R.J., White, J.M., 2014. Towards finding a population biomarker for wastewater epidemiology studies. Sci. Total Environ. 487, 621-628. doi:10.1016/j.scitotenv.2013.11.075

Chen, C., Kostakis, C., Irvine, R.J., White, J.M., 2013. Increases in use of novel synthetic stimulant are not directly linked to decreased use of 3,4-methylenedioxy-N-methylamphetamine (MDMA). Forensic Sci. Int. 231, 278-283. doi:10.1016/j.forsciint.2013.06.007

Chiaia, A.C., Banta-green, C., Field, J., 2008. Eliminating solid phase extraction with large-volume Injection LC/MS/MS: analysis of illicit and legal drugs and human urine indicators in US wastewaters 42, 8841-8848. doi:10.1021/es802309v

Collins, M., 2011. Some new psychoactive substances: Precursor chemicals and synthesis-driven end-products. Drug Test. Anal. 3, 404-416. doi:10.1002/dta.315

Colomer-Lluch, M., Calero Caceres, W., Jebri, S., Hmaied, F., Muniesa, M., Jofre, J., 2014. 
Antibiotic resistance genes in bacterial and bacteriophage fractions of Tunisian and Spanish wastewaters as markers to compare the antibiotic resistance patterns in each population. Environ. Int. 73, 167-175. doi:10.1016/j.envint.2014.07.003

Comission Regulation 1881/2006, 2006. , Official Journal of the European Union, L 364/5.

Coscollà, C., Colin, P., Yahyaoui, A., Petrique, O., Yusà, V., Mellouki, A., Pastor, A., 2010. Occurrence of currently used pesticides in ambient air of Centre Region (France). Atmos. Environ. 44, 3915-3925. doi:10.1016/j.atmosenv.2010.07.014

Coutu, S., Wyrsch, V., Wynn, H.K., Rossi, L., Barry, D.A., 2013. Temporal dynamics of antibiotics in wastewater treatment plant influent. Sci. Total Environ. 458-460, 20-26. doi:10.1016/j.scitotenv.2013.04.017

Crews, H., Olivier, L., Wilson, L., 2001. Urinary biomarkers for assessing dietary exposure to caffeine. Food Addit Contam. 18, 1075-1087. doi:10.1080/02652030110056630

Curtin, F., Walker, J., Schulz, P., 1996. Day-to-day intraindividual reliability and interindividual differences in monoamines excretion. J. Affect. Disord. 38, 173-178.

Dahl, H., Hammarberg, A., Franck, J., Helander, A., 2011. Urinary ethyl glucuronide and ethyl sulfate testing for recent drinking in alcohol-dependent outpatients treated with acamprosate or placebo. Alcohol Alcohol. 46, 553-557. doi:10.1093/alcalc/agr055

Dahl, H., Stephanson, N., Beck, O., Helander, A., 2002. Comparison of urinary excretion characteristics of ethanol and ethyl glucuronide. J. Anal. Toxicol. 26, 201-204.

Daughton, 2012a. Real-time estimation of small-area populations with human biomarkers in sewage. Sci. Total Environ. 414, 6-21. doi:10.1016/j.scitotenv.2011.11.015

Daughton, 2012b. Using biomarkers in sewage to monitor community-wide human health: Isoprostanes as conceptual prototype. Sci. Total Environ. 424, 16-38. doi:10.1016/j.scitotenv.2012.02.038

Daughton, C.G., 2001. Illicit Drugs in Municipal Sewage, in: Pharmaceuticals and Care Products in the Environment. pp. 348-364. doi:10.1021/bk-2001-0791.ch020

Daughton, C.G., Ruhoy, I.S., 2009. Environmental Footprint of Pharmaceuticals: the Significance of Factors Beyond Direct Excretion To Sewers. Environ. Toxicol. Chem. 28, 2495. doi:10.1897/08-382.1

De Boer, D., Bosman, I.J., Hidvégi, E., Manzoni, C., Benkö, A.A., Dos Reys, L.J.A.L., Maes, R.A.A., 2001. Piperazine-like compounds: A new group of designer drugs-of-abuse on the European market. Forensic Sci. Int. 121, 47-56. doi:10.1016/S0379-0738(01)00452-2

Dejean, T., Valentini, A., Duparc, A., Pellier-Cuit, S., Pompanon, F., Taberlet, P., Miaud, C., 2011. Persistence of environmental DNA in freshwater ecosystems. PLoS One 6, 8-11. doi:10.1371/journal.pone.0023398

Dewalque, L., Pirard, C., Charlier, C., 2014. Measurement of urinary biomarkers of parabens, benzophenone-3, and phthalates in a Belgian population. Biomed Res. Int. 2014. doi:10.1155/2014/649314

Dresen, S., Weinmann, W., Wurst, F.M., 2004. Forensic confirmatory analysis of ethyl sulfate - A new marker for alcohol consumption - By liquid-chromatography/electrospray ionization/tandem mass spectrometry. J. Am. Soc. Mass Spectrom. 15, 1644-1648. doi:10.1016/j.jasms.2004.08.004

Ellefsen, K.N., Wohlfarth, A., Swortwood, M.J., Diao, X., Concheiro, M., Huestis, M.A., 2015. 4Methoxy- $\alpha$-PVP: in silico prediction, metabolic stability, and metabolite identification by human hepatocyte incubation and high-resolution mass spectrometry. Forensic Toxicol. 34, 61-75. doi:10.1007/s11419-015-0287-4

EMCDDA, 2016. Assessing illicit drugs in wastewater. Advances in wastewater-based drug epidemiology, Assessing illicit drugs in wastewater: advances in wastewater-based drug epidemiology, EMCDDA Insights 22. doi:10.2810/017397

EMCDDA, 2015a. New psychoactive substances in Europe. An update from the EU Early Warning System (March 2015). 
EMCDDA, 2015b. European Drug Report: Trends and Developments.

EMCDDA, 2014. Methoxetamine - Report on the risk assessment of 2-(3-methoxyphenyl)-2(ethylamino)cyclohexanone (methoxetamine) in the framework of the Council Decision on new psychoactive substances. Risk assessments 26. doi:10.2810/44197

Emke, E., Evans, S., Kasprzyk-Hordern, B., de Voogt, P., 2014. Enantiomer profiling of high loads of amphetamine and MDMA in communal sewage: a Dutch perspective. Sci. Total Environ. 487, 666-72. doi:10.1016/j.scitotenv.2013.11.043

EPCD, 2003. European parliament and council directive (EPCD) 2003/115/EC of 22 December 2003 amending directive 94/35/EC on sweeteners for use in foodstuffs. EPCD.

Euro-CDC, 2012. Summary of the latest data on antibiotic resistance in the European Union. EuroCdc.

European Food Safety Authority, 2013. Annual Report 2013 Annual Report of the European Food Safety Authority for 2013 1-36.

European Union, 2005. Council Decision 2005/387/JHA on the information exchange, risk assessment and control of new psychoactive substances.

Ewald, A.H., Ehlers, D., Maurer, H.H., 2008. Metabolism and toxicological detection of the designer drug 4-chloro-2,5-dimethoxyamphetamine in rat urine using gas chromatographymass spectrometry. Anal. Bioanal. Chem. 390, 1837-1842. doi:10.1007/s00216-008-1917-z

Ewald, A.H., Fritschi, G., Bork, W.R., Maurer, H.H., 2006. Designer drugs 2,5-dimethoxy-4bromo-amphetamine (DOB) and 2,5-dimethoxy-4-bromo-methamphetamine (MDOB): Studies on their metabolism and toxicological detection in rat urine using gas chromatographic/mass spectrometric techniques. J. Mass Spectrom. 41, 487-498. doi:10.1002/jms.1007

Fantegrossi, W.E., Moran, J.H., Radominska-Pandya, A., Prather, P.L., 2014. Distinct pharmacology and metabolism of $\mathrm{K} 2$ synthetic cannabinoids compared to $\triangle 9-\mathrm{THC}$ : Mechanism underlying greater toxicity? Life Sci. 97, 45-54. doi:10.1016/j.1fs.2013.09.017

Feldman, M., Lee, M., 1985. Serotonin content on foods: effect on urinary excretion of 5hydroxyindoleacetic acid. Am. J. Clin. Nutr. 42, 639-643.

Fermin, L., Vallvey, C., 2004. Intense sweeteners. Handbook of Food Analysis: Residues and other food component analysis:Volume 2. Chapter 43 Intense Sweeteners.

Fernández, P., Regenjo, M., Fernández, A.M., Lorenzo, R.A., Carro, A.M., 2014. Optimization of ultrasound-assisted dispersive liquid-liquid microextraction for ultra performance liquid chromatography determination of benzodiazepines in urine and hospital wastewater. Anal. Methods 6, 8239-8246. doi:10.1039/c4ay01348d

Fitzsimons, M.F., Belt, S.T., 2005. Dynamic behaviour of 1-aminopropan-2-one in sewage: a preliminary synthetic and spectroscopic study. Environ. Chem. Lett. 3, 70-73. doi:10.1007/s 10311-005-0005-2

Fromme, H., Gareis, M., Völkel, W., Gottschalk, C., 2016. Overall internal exposure to mycotoxins and their occurrence in occupational and residential settings - An overview. Int. J. Hyg. Environ. Health 219, 143-165. doi:http://dx.doi.org/10.1016/j.ijheh.2015.11.004

Fromme, H., Schütze, A., Lahrz, T., Kraft, M., Fembacher, L., Siewering, S., Burkardt, R., Dietrich, S., Koch, H.M., Völkel, W., 2016. Non-phthalate plasticizers in German daycare centers and human biomonitoring of DINCH metabolites in children attending the centers (LUPE 3). Int. J. Hyg. Environ. Health 219, 33-39. doi:10.1016/j.ijheh.2015.08.002

Gago-Ferrero, P., Díaz-Cruz, M.S., Barceló, D., 2011. Occurrence of multiclass UV filters in treated sewage sludge from wastewater treatment plants. Chemosphere 84, 1158-1165. doi:10.1016/j.chemosphere.2011.04.003

Gao, D.W., Wen, Z.D., 2016. Phthalate esters in the environment: A critical review of their occurrence, biodegradation, and removal during wastewater treatment processes. Sci. Total Environ. 541, 986-1001. doi:10.1016/j.scitotenv.2015.09.148

Garattini, S., 1993. Caffeine, Coffee and Health. Raven Press, New York.

Gasser, G., Rona, M., Voloshenko, A., Shelkov, R., Tal, N., Pankratov, I., Elhanany, S., Lev, O., 
2010. Quantitative evaluation of tracers for quantification of wastewater contamination of potable water sources. Environ. Sci. Technol. 44, 3919-3925. doi:10.1021/es100604c

Gatidou, G., Kinyua, J., van Nuijs, A.L.N., Gracia-Lor, E., Castiglioni, S., Covaci, A., Stasinakis, A.S., 2016. Drugs of abuse and alcohol consumption among different groups of population on the Greek Island of Lesvos through sewage-based epidemiology. Sci. Total Environ. 563-564, 633-640. doi:10.1016/j.scitotenv.2016.04.130

González-Mariño, I., Gracia-Lor, E., Bagnati, R., Martins, C.P.B., Zuccato, E., Castiglioni, S., 2016a. Screening new psychoactive substances in urban wastewater using High Resolution Mass Spectrometry. Anal. Bioanal. Chem. 408, 4297-4309.

González-Mariño, I., Gracia-Lor, E., Rousis, N.I., Castrignanò, E., Thomas, K. V, Quintana, J.B., Kasprzyk-Hordern, B., Zuccato, E., Castiglioni, S., 2016b. Wastewater-based epidemiology to monitor synthetic cathinones use in different European countries. Environ. Sci. Technol. doi:10.1021/acs.est.6b02644

González-Mariño, I., Quintana, J.B., Rodríguez, I., Cela, R., 2010. Determination of drugs of abuse in water by solid-phase extraction, derivatisation and gas chromatography-ion trap-tandem mass spectrometry. J. Chromatogr. A 1217, 1748-1760. doi:10.1016/j.chroma.2010.01.046

González-Mariño, I., Quintana, J.B., Rodríguez, I., Cela, R., 2009. Simultaneous determination of parabens, triclosan and triclocarban in water by liquid chromatography/electrospray ionisation tandem mass spectrometry. Rapid Commun. Mass Spectrom. 23, 1756-1766. doi:10.1002/rcm

Gorrod, J.W., Wahren, J., 1993. Nicotine and Related Alkaloids - Absorption, distribution, metabolism and excretion. Springer.

Gracia-Lor, E., Martínez, M., Sancho, J. V., Peñuela, G., Hernández, F., 2012a. Multi-class determination of personal care products and pharmaceuticals in environmental and wastewater samples by ultra-high performance liquid-chromatography-tandem mass spectrometry. Talanta 99, 1011-1023. doi:10.1016/j.talanta.2012.07.091

Gracia-Lor, E., Sancho, J. V., Serrano, R., Hernández, F., 2012b. Occurrence and removal of pharmaceuticals in wastewater treatment plants at the Spanish Mediterranean area of Valencia. Chemosphere 87, 453-462. doi:10.1016/j.chemosphere.2011.12.025

Gracia-Lor, E., Zuccato, E., Castiglioni, S., 2016. Refining correction factors for back-calculation of illicit drug use. Sci. Total Environ. 573, 1648-1659. doi:10.1016/j.scitotenv.2016.09.179

Grant, D.M., Tang, B.K., Kalow, W., 1983. Variability in caffeine metabolism. Clin. Pharmacol. Ther. 33, 591-602. doi:10.1038/clpt.1983.80

Group, B.D.W., 2001. Biomarkers and surrogate endpoints: Preferred definitions and conceptual framework. Clin. Pharmacol. Ther. 69, 89-95. doi:10.1067/mcp.2001.113989

Guo, Y., Alomirah, H., Cho, H.-S., Minh, T.B., Mohd, M.A., Nakata, H., Kannan, K., 2011. Occurrence of phthalate metabolites in human urine from several Asian countries. Environ. Sci. Technol. 45, 3138-44. doi:10.1021/es103879m

Hagger, J.A., Jones, M.B., Leonard, D.P., Owen, R., Galloway, T.S., 2006. Biomarkers and integrated environmental risk assessment: Are there more questions than answers? Integr. Environ. Assess. Manag. 2, 312-329. doi:10.1002/ieam.5630020403

Halter, C.C., Dresen, S., Auwaerter, V., Wurst, F.M., Weinmann, W., 2008. Kinetics in serum and urinary excretion of ethyl sulfate and ethyl glucuronide after medium dose ethanol intake. Int. J. Legal Med. 122, 123-128. doi:10.1007/s00414-007-0180-8

Helander, A., Beck, O., 2005. Ethyl sulfate: a metabolite of ethanol in humans and a potential biomarker of acute alcohol intake. J. Anal. Toxicol. 29, 270-274.

Helfer, A.G., Turcant, A., Boels, D., Ferec, S., Lelievre, B., Welter, J., Meyer, M.R., Maurer, H.H., 2007. Elucidation of the metabolites of the novel psychoactive substance 4-methyl-N-ethylcathinone (4-MEC) in human urine and pooled liver microsomes by GC-MS and LC-HRMS/MS techniques and of its detectability by GC-MS or LC-MS(n) standard screening approache. Drug Test. Anal. 7, 368-375.

Hellmér, M., Paxéus, N., Magnius, L., Enache, L., Arnholm, B., Johansson, A., Bergström, T., 
Norder, H., 2014. Detection of pathogenic viruses in sewage provided early warnings of hepatitis A virus and norovirus outbreaks. Appl. Environ. Microbiol. 80, 6771-6781. doi:10.1128/AEM.01981-14

Hernández, A.F., Parrón, T., Tsatsakis, A.M., Requena, M., Alarcón, R., López-Guarnido, O., 2013. Toxic effects of pesticide mixtures at a molecular level: Their relevance to human health. Toxicology 307, 136-145. doi:10.1016/j.tox.2012.06.009

Hernández, F., Castiglioni, S., Covaci, A., Voogt, P. de, Emke, E., Kasprzyk-Hordern, B., Ort, C., Reid, M., Sancho, J. V., van Nuijs, Alexander L.N Zuccato, E., Bijlsma, L., 2016. Mass spectrometric strategies for the investigation of biomarkers of illicit drug use in wastewater. Mass Spectrom. Rev. doi:DOI 10.1002/mas.21525

Herrero, L., Calvarro, S., Fernández, M.A., Quintanilla-López, J.E., González, M.J., Gómara, B., 2015. Feasibility of ultra-high performance liquid and gas chromatography coupled to mass spectrometry for accurate determination of primary and secondary phthalate metabolites in urine samples. Anal. Chim. Acta 853, 625-636. doi:10.1016/j.aca.2014.09.043

Heyndrickx, E., Sioen, I., Huybrechts, B., Callebaut, A., De Henauw, S., De Saeger, S., 2015. Human biomonitoring of multiple mycotoxins in the Belgian population: Results of the BIOMYCO study. Environ. Int. 84, 82-89. doi:10.1016/j.envint.2015.06.011

Høiseth, G., Bernard, J.P., Stephanson, N., Normann, P.T., Christophersen, A.S., Mørland, J., Helander, A., 2008. Comparison between the urinary alcohol markers EtG, EtS, and GTOL/5HIAA in a controlled drinking experiment. Alcohol Alcohol. 43, 187-191. doi:10.1093/alcalc/agm 175

Hu, P., Chen, X., Whitener, R.J., Boder, E.T., Jones, J.O., Porollo, A., Chen, J., Zhao, L., 2013. Effects of parabens on adipocyte differentiation. Toxicol. Sci. 131, 56-70. doi:10.1093/toxsci/kfs262

Huang, C., Renew, J.E., Smeby, K.L., Pinkston, K., Sedlak, D.L., 2011. Assessment of potential anbibiotic contaminants in water and preliminary occurrence analysis. J. Contemp. Water Res. Educ. 120, 4.

Hukkanen, J., 2005. Metabolism and Disposition Kinetics of Nicotine. Pharmacol. Rev. 57, 79-115. doi:10.1124/pr.57.1.3

Hummel, D., Löffler, D., Fink, G., Ternes, T. a, 2006. Simultaneous determination of psychoactive drugs and their metabolites in aqueous matrices by liquid chromatography mass Spectrometry. Environ. Sci. Technol. 40, 7321-8.

Huppertz, L.M., Bisel, P., Westphal, F., Franz, F., Auwarter, V., Moosmann, B., 2015. Characterization of the four designer benzodiazepines clonazolam, deschloroetizolam, flubromazolam, and meclonazepam, and identification of their in vitro metabolites. Forensic Toxicol. 33, 388-395. doi:10.1007/s11419-015-0277-6

Hutter, M., Broecker, S., Kneisel, S., Auwärter, V., 2012. Identification of the major urinary metabolites in man of seven synthetic cannabinoids of the aminoalkylindole type present as adulterants in "herbal mixtures" using LC-MS/MS techniques. J. Mass Spectrom. 47, 54-65. doi:10.1002/jms.2026

Hyde, J.F., Adams, R., 1928. Synthetic homologs of d,1-ephedrine. J. Am. Chem. Soc. 50, 22872292.

Jelic, A., Gros, M., Petrovic, M., Ginebreda, A., Barceló, D., 2012. Occurrence and elimination of pharmaceuticals during conventional wastewater treatment. Emerg. Prior. Pollut. Rivers 1-23. doi:10.1007/978-3-642-25722-3

Johnson, R.D., Botch-Jones, S.R., 2013. The Stability of Four Designer Drugs: MDPV, Mephedrone, BZP and TFMPP in Three Biological Matrices under Various Storage Conditions. J. Anal. Toxicol. 37, 51-55. doi:10.1093/jat/bks138

Joint Fao Oms Expert Committee On Food Additives, 2010. Toxicological and Health Aspects of Bisphenol A Joint FAO / WHO Expert Meeting. Fao Who 60.

Jones, A.W., 1990. Excretion of alcohol in urine and diuresis in healthy men in relation to their age, 
the dose administered and the time after drinking. Forensic Sci. Int. 45, 217-224.

Kamata, T., Katagi, M., Kamata, H.T.., Miki, A., Shima, N., Zaitsu, K., Nishikawa, M., Tanaka, H., Honda, K., Tsuchihashi, H., 2006. Metabolism of the psychotomimetic tryptamine derivative 5-methoxy-N,N-diisopropyltrytamine in humans: identificafion and quantification of its urinary metabolites. Drug Metab. Dispos. 34, 281-28. doi:10.1124/dmd.105.005835.United

Kasprzyk-Hordern, B., Baker, D.R., 2012. Enantiomeric profiling of chiral drugs in wastewater and receiving waters. Environ. Sci. Technol. 46, 1681-1691. doi:10.1021/es203113y

Kasprzyk-Hordern, B., Dinsdale, R.M., Guwy, A.J., 2008. Multiresidue methods for the analysis of pharmaceuticals, personal care products and illicit drugs in surface water and wastewater by solid-phase extraction and ultra performance liquid chromatography-electrospray tandem mass spectrometry. Anal. Bioanal. Chem. 391, 1293-1308. doi:10.1007/s00216-008-1854-x

Khan, U., Nicell, J. a., 2011. Refined sewer epidemiology mass balances and their application to heroin, cocaine and ecstasy. Environ. Int. 37, 1236-1252. doi:10.1016/j.envint.2011.05.009

Kim, M.J., Kwack, S.J., Lim, S.K., Kim, Y.J., Roh, T.H., Choi, S.M., Kim, H.S., Lee, B.M., 2015. Toxicological evaluation of isopropylparaben and isobutylparaben mixture in Sprague-Dawley rats following 28 days of dermal exposure. Regul. Toxicol. Pharmacol. 73, 544-51. doi:10.1016/j.yrtph.2015.08.005

Kinyua, J., Covaci, A., Maho, W., McCall, A.-K., Neels, H., van Nuijs, A.L.N., 2015. Sewagebased epidemiology in monitoring the use of new psychoactive substances: Validation and application of an analytical method using LC-MS/MS. Drug Test. Anal. 7, 812-818. doi:10.1002/dta.1777

Kokkinos, P., Ziros, P., Meri, D., Filippidou, S., Kolla, S., Galanis, A., Vantarakis, A., 2011. Environmental surveillance. An additional/alternative approach for virological surveillance in Greece? Int. J. Environ. Res. Public Health 8, 1914-1922. doi:10.3390/ijerph8061914

Kokotou, M.G., Asimakopoulos, A.G., Thomaidis, N.S., 2012. Artificial sweeteners as emerging pollutants in the environment: Analytical methodologies and environmental impact. Anal. Methods 4, 3057-3070.

Kokotou, M.G., Asimakopoulosa, A., Thomaidis, N.S., 2013. Determination of eight artificial sweeteners in wastewater by hydrophilic interaction liquid chromatography-tandem mass spectrometry. Anal. Methods 5, 3825. doi:10.1039/c3ay40599k

Kolpin, D.W., Schenzel, J., Meyer, M.T., Phillips, P.J., Hubbard, L.E., Scott, T.M., Bucheli, T.D., 2014. Mycotoxins: Diffuse and point source contributions of natural contaminants of emerging concern to streams. Sci. Total Environ. 470-471, 669-676. doi:10.1016/j.scitotenv.2013.09.062

Kosjek, T., Perko, S., Zupanc, M., ZanoŠki Hren, M., Landeka Dragičević, T., Žigon, D., Kompare, B., Heath, E., 2012. Environmental occurrence, fate and transformation of benzodiazepines in water treatment. Water Res. 46, 355-368. doi:10.1016/j.watres.2011.10.056

Kumaraswamy, R., Amha, Y.M., Anwar, M.Z., Henschel, A., Rodríguez, J., Ahmad, F., 2014. Molecular analysis for screening human bacterial pathogens in municipal wastewater treatment and reuse. Environ. Sci. Technol. 48, 11610-9. doi:10.1021/es502546t

Kümmerer, K., 2009. Antibiotics in the aquatic environment - A review - Part I. Chemosphere 75, 417-434. doi:10.1016/j.chemosphere.2008.11.086

Laganà, A., Bacaloni, A., De Leva, I., Faberi, A., Fago, G., Marino, A., 2004. Analytical methodologies for determining the occurrence of endocrine disrupting chemicals in sewage treatment plants and natural waters. Anal. Chim. Acta 501, 79-88. doi:10.1016/j.aca.2003.09.020

Lai, F.Y., Anuj, S., Bruno, R., Carter, S., Gartner, C., Hall, W., Kirkbride, K.P., Mueller, J.F., O'Brien, J.W., Prichard, J., Thai, P.K., Ort, C., 2015a. Systematic and day-to-day effects of chemical-derived population estimates on wastewater-based drug epidemiology. Environ. Sci. Technol. 49, 999-1008. doi:10.1021/es503474d

Lai, F.Y., Erratico, C., Kinyua, J., Mueller, J.F., Covaci, A., van Nuijs, A.L.N., 2015b. Liquid 
chromatography-quadrupole time-of-flight mass spectrometry for screening in vitro drug metabolites in humans: Investigation on seven phenethylamine-based designer drugs. J. Pharm. Biomed. Anal. 114, 355-375. doi:10.1016/j.jpba.2015.06.016

Lai, F.Y., Ort, C., Gartner, C., Carter, S., Prichard, J., Kirkbride, P., Bruno, R., Hall, W., Eaglesham, G., Mueller, J.F., 2011. Refining the estimation of illicit drug consumptions from wastewater analysis: Co-analysis of prescription pharmaceuticals and uncertainty assessment. Water Res. 45, 4437-4448. doi:10.1016/j.watres.2011.05.042

Lange, F.T., Scheurer, M., Brauch, H.J., 2012. Artificial sweeteners-A recently recognized class of emerging environmental contaminants: A review. Anal. Bioanal. Chem. 403, 2503-2518. doi:10.1007/s00216-012-5892-z

Le Chatelier, E., Nielsen, T., Qin, J., Prifti, E., Hildebrand, F., Falony, G., Almeida, M., Arumugam, M., Batto, J.-M., Kennedy, S., Leonard, P., Li, J., Burgdorf, K., Grarup, N., Jørgensen, T., Brandslund, I., Nielsen, H.B., Juncker, A.S., Bertalan, M., Levenez, F., Pons, N., Rasmussen, S., Sunagawa, S., Tap, J., Tims, S., Zoetendal, E.G., Brunak, S., Clément, K., Doré, J., Kleerebezem, M., Kristiansen, K., Renault, P., Sicheritz-Ponten, T., de Vos, W.M., Zucker, J.-D., Raes, J., Hansen, T., Bork, P., Wang, J., Ehrlich, S.D., Pedersen, O., Guedon, E., Delorme, C., Layec, S., Khaci, G., van de Guchte, M., Vandemeulebrouck, G., Jamet, A., Dervyn, R., Sanchez, N., Maguin, E., Haimet, F., Winogradski, Y., Cultrone, A., Leclerc, M., Juste, C., Blottière, H., Pelletier, E., LePaslier, D., Artiguenave, F., Bruls, T., Weissenbach, J., Turner, K., Parkhill, J., Antolin, M., Manichanh, C., Casellas, F., Boruel, N., Varela, E., Torrejon, A., Guarner, F., Denariaz, G., Derrien, M., van Hylckama Vlieg, J.E.T., Veiga, P., Oozeer, R., Knol, J., Rescigno, M., Brechot, C., M’Rini, C., Mérieux, A., Yamada, T., 2013. Richness of human gut microbiome correlates with metabolic markers. Nature 500, 541-6. doi:10.1038/nature12506

Le Fol, V., Aït-Aïssa, S., Cabaton, N., Dolo, L., Grimaldi, M., Balaguer, P., Perdu, E., Debrauwer, L., Brion, F., Zalko, D., 2015. Cell-specific biotransformation of benzophenone-2 and bisphenol-s in zebrafish and human in vitro models used for toxicity and estrogenicity screening. Environ. Sci. Technol. 49, 3860-3868. doi:10.1021/es505302c

Liu, S., Wu, P., Li, W., Zhang, H., Cai, C., 2011. An electrochemical approach for detection of DNA methylation and assay of the methyltransferase activity. Chem. Commun. (Camb). 47, 2844-6. doi:10.1039/c0cc05153e

Löffler, D., Römbke, J., M, M., Ternes TA., 2005. Environmental fate of pharmaceuticals in water/sediment systems. Environ. Sci. Technol. 39, 5209-5218.

Loftus, N.J., Laird, W.J.D., Steel, G.T., Wilks, M.F., Woollen, B.H., 1993. Metabolism and pharmacokinetics of deuterium-labelled di-2-(ethylhexyl) adipate (DEHA) in humans. Food Chem. Toxicol. 31, 609-614. doi:10.1016/0278-6915(93)90042-W

Loos, R., Carvalho, R., Comero, S., António, D., Ghiani, M., Lettieri, T., Locoro, G., Paracchini, B., Tavazzi, S., Gawlik, B., Blaha, L., Jarosova, B., Voorspoels, S., Schwesig, D., Haglund, P., Fick, J., Gans, O., 2012. EU Wide Monitoring Survey on Waste Water Treatment Plant Effluents, JRC scientific and policy report. doi:10.2788/60663

Lopes, A., Silva, N., Bronze, M.R., Ferreira, J., Morais, J., 2014. Analysis of cocaine and nicotine metabolites in wastewater by liquid chromatography-tandem mass spectrometry. Cross abuse index patterns on a major community. Sci. Total Environ. 487, 673-680. doi:10.1016/j.scitotenv.2013.10.042

Lostia, A.M., Vicente, J.L., Cowan, D.A., 2013. Measurement of ethyl glucuronide, ethyl sulphate and their ratio in the urine and serum of healthy volunteers after two doses of alcohol. Alcohol Alcohol. 48, 74-82. doi:10.1093/alcalc/ags 108

Louis, G.M.B., Chen, Z., Kim, S., Sapra, K., Phil, M., Bae, J., Kannan, K., 2015. Urinary concentrations of benzophenone-type ultraviolet light filters and semen quality. Fertil. Steril. 104, 989-996.

Louis, G.M.B., Kannan, K., Sapra, K.J., Maisog, J., Sundaram, R., 2014. Urinary concentrations of 
benzophenone-type ultraviolet radiation filters and couples' fecundity. Am. J. Epidemiol. 180, 1168-1175. doi:10.1093/aje/kwu285

Lyssimachou, A., Santos, J.G., André, A., Soares, J., Lima, D., Guimarães, L., Almeida, C.M.R., Teixeira, C., Castro, L.F.C., Santos, M.M., 2015. The Mammalian “Obesogen” Tributyltin Targets Hepatic Triglyceride Accumulation and the Transcriptional Regulation of Lipid Metabolism in the Liver and Brain of Zebrafish. PLoS One 10, e0143911. doi:10.1371/journal.pone.0143911

Mackul'ak, T., Birošová, L., Grabic, R., Škubák, J., Bodík, I., 2015. National monitoring of nicotine use in Czech and Slovak Republic based on wastewater analysis. Environ. Sci. Pollut. Res. doi:10.1007/s11356-015-4648-7

Managaki, S., Takada, H., Kim, D.M., Horiguchi, T., Shiraishi, H., 2006. Three-dimensional distributions of sewage markers in Tokyo Bay water - Fluorescent whitening agents (FWAs). Mar. Pollut. Bull. 52, 281-292. doi:10.1016/j.marpolbul.2005.08.025

Mardal, M., Meyer, M.R., 2014. Studies on the microbial biotransformation of the novel psychoactive substance methylenedioxypyrovalerone (MDPV) in wastewater by means of liquid chromatography-high resolution mass spectrometry/mass spectrometry. Sci. Total Environ. 493, 588-595. doi:10.1016/j.scitotenv.2014.06.016

Mardal, M., Miserez, B., Bade, R., Portolés, T., Bischoff, M., Hernández, F., Meyer, M.R., 2016. 3Fluorophenmetrazine, a fluorinated analogue of phenmetrazine: Studies on in vivo metabolism in rat and human, in vitro metabolism in human CYP isoenzymes and microbial biotransformation in Pseudomonas Putida and wastewater using GC and LC coupled to (HR. J. Pharm. Biomed. Anal. 128, 485-495. doi:10.1016/j.jpba.2016.06.011

Marklund, A., Andersson, B., Haglund, P., 2005. Organophosphorus flame retardants and plasticizers in Swedish sewage treatment plants. Environ. Sci. Technol. 39, 7423-7429. doi:10.1021/es0510131

Marroquín-Cardona, A.G., Johnson, N.M., Phillips, T.D., Hayes, A.W., 2014. Mycotoxins in a changing global environment - A review. Food Chem. Toxicol. 69, 220-230. doi:10.1016/j.fct.2014.04.025

Martínez-Bueno, M.J., Uclés, S., Hernando, M.D., Davoli, E., Fernández-Alba, A.R., 2011. Evaluation of selected ubiquitous contaminants in the aquatic environment and their transformation products. A pilot study of their removal from a sewage treatment plant. Water Res. 45, 2331-2341. doi:10.1016/j.watres.2011.01.011

Mastroianni, N., Lopez de Alda, M., Barcelo, D., 2014. Analysis of ethyl sulfate in raw wastewater for estimation of alcohol consumption and its correlation with drugs of abuse in the city of Barcelona. J. Chromatogr. A 1360, 93-99. doi:10.1016/j.chroma.2014.07.051

Maurer, H.H., Kraemer, T., Springer, D., Staack, R.F., 2004. Chemistry, pharmacology, toxicology, and hepatic metabolism of designer drugs of the amphetamine (ecstasy), piperazine, and pyrrolidinophenone types: a synopsis. Ther. Drug Monit. 26, 127-131.

McCall, A.-K., Bade, R., Kinyua, J., Lai, F.Y., Thai, P.K., Covaci, A., Bijlsma, L., van Nuijs, A.L.N., Ort, C., 2016a. Critical review on the stability of illicit drugs in sewers and wastewater samples. Water Res. 88, 933-947. doi:10.1016/j.watres.2015.10.040

McCall, A.-K., Scheidegger, A., Madry, M.M., Steuer, A.E., Weissbrodt, D.G., Vanrolleghem, P.A., Kraemer, T., Morgenroth, E., Ort, C., 2016b. Influence of Different Sewer Biofilms on Transformation Rates of Drugs. Submitted.

McLellan, S.L., Eren, A.M., 2014. Discovering new indicators of fecal pollution. Trends Microbiol. 22, 697-706. doi:10.1016/j.tim.2014.08.002

Mclellan, S.L., Newton, R.J., Vandewalle, J.L., Shanks, O.C., Huse, S.M., Eren, A.M., Sogin, M.L., 2013. Sewage reflects the distribution of human faecal lachnospiraceae. Environ. Microbiol. 15, 2213-2227. doi:10.1111/1462-2920.12092

Meyer, M.R., Bach, M., Welter, J., Bovens, M., Turcant, A., Maurer, H.H., 2013. Ketamine-derived designer drug methoxetamine: Metabolism including isoenzyme kinetics and toxicological 
detectability using GC-MS and LC-(HR-)MSn. Anal. Bioanal. Chem. 405, 6307-6321. doi:10.1007/s00216-013-7051-6

Meyer, M.R., Du, P., Schuster, F., Maurer, H.H., 2010a. Studies on the metabolism of the $\alpha-$ pyrrolidinophenone designer drug methylenedioxy-pyrovalerone (MDPV) in rat and human urine and human liver microsomes using GC-MS and LC-high-resolution MS and its detectability in urine by GC-MS. J. Mass Spectrom. 45, 1426-1442. doi:10.1002/jms.1859

Meyer, M.R., Mauer, S., Meyer, G.M., Dinger, J., Klein, B., Westphal, F., Maurer, H.H., 2014. The in vivo and in vitro metabolism and the detectability in urine of 3',4'-methylenedioxy-alphapyrrolidinobutyrophenone (MDPBP), a new pyrrolidinophenone-type designer drug, studied by GC-MS and LC-MS(n). Drug Test. Anal. 6, 746-756.

Meyer, M.R., Maurer, H.H., 2010. Metabolism of Designer Drugs of Abuse: An Updated Review. Curr. Drug Metab. 11, 468-482. doi:10.2174/138920010791526042

Meyer, M.R., Vollmar, C., Schwaninger, A.E., Wolf, E.U., Maurer, H.H., 2012. New cathinonederived designer drugs 3-bromomethcathinone and 3-fluoromethcathinone: Studies on their metabolism in rat urine and human liver microsomes using GC-MS and LC-high-resolution MS and their detectability in urine. J. Mass Spectrom. 47, 253-262. doi:10.1002/jms.2960

Meyer, M.R., Wilhelm, J., Peters, F.T., Maurer, H.H., 2010b. Beta-keto amphetamines: Studies on the metabolism of the designer drug mephedrone and toxicological detection of mephedrone, butylone, and methylone in urine using gas chromatography - Mass spectrometry. Anal. Bioanal. Chem. 397, 1225-1233. doi:10.1007/s00216-010-3636-5

Michely, J.A., Helfer, A.G., Brandt, S.D., Meyer, M.R., Maurer, H.H., 2015. Metabolism of the new psychoactive substances N,N-diallyltryptamine (DALT) and 5-methoxy-DALT and their detectability in urine by GC-MS, LC-MS n , and LC-HR-MS-MS. Anal. Bioanal. Chem. 407, 7831-7842. doi:10.1007/s00216-015-8955-0

Moosmann, B., Huppertz, L.M., Hutter, M., Buchwald, A., Ferlaino, S., Auwärter, V., 2013. Detection and identification of the designer benzodiazepine flubromazepam and preliminary data on its metabolism and pharmacokinetics. J. Mass Spectrom. 48, 1150-1159. doi:10.1002/jms.3279

Mwenesongole, E.M., Lata Gautam, S.W.H., Waterhousea, John W. Colea, M.D., 2013. Simultaneous detection of controlled substances in waste water. Anal. Methods 5, 3248-3254.

Narimatsu, S., Yonemoto, R., Masuda, K., Katsu, T., Asanuma, M., Kamata, T., Katagi, M., Tsuchihashi, H., Kumamoto, T., Ishikawa, T., Naito, S., Yamano, S., Hanioka, N., 2008. Oxidation of 5-methoxy-N,N-diisopropyltryptamine in rat liver microsomes and recombinant cytochrome P450 enzymes. Biochem. Pharmacol. 75, 752-760. doi:10.1016/j.bcp.2007.09.019

Newton, R.J., McLellan, S.L., Dila, D.K., Vineis, J.H., Morrison, H.G., Murat Eren, A., Sogin, M.L., 2015. Sewage reflects the microbiomes of human populations. MBio 6, 1-9. doi:10.1128/mBio.02574-14

Ntzani, E.E., Chondrogiorgi, M., Ntritsos, G., Evangelou, E., Tzoulaki, I., 2013. Literature review on epidemiological studies linking exposure to pesticides. EFSA supporting publication 2013:EN-497.

O’Brien, J.W., Thai, P.K., Brandsma, S.H., Leonards, P.E.G., Ort, C., Mueller, J.F., 2015. Wastewater analysis of Census day samples to investigate per capita input of organophosphorus flame retardants and plasticizers into wastewater. Chemosphere 138, 328334. doi:10.1016/j.chemosphere.2015.06.014

O’Brien, J.W., Thai, P.K., Eaglesham, G., Ort, C., Scheidegger, A., Carter, S., Lai, F.Y., Mueller, J.F., 2014. A Model to Estimate the Population Contributing to the Wastewater Using Samples Collected on Census Day. Environ. Sci. Technol. 48, 517-525. doi:10.1021/es403251g

Ocaña-González, J.A., Villar-Navarro, M., Ramos-Payán, M., Fernández-Torres, R., Bello-López, M.A., 2015. New developments in the extraction and determination of parabens in cosmetics and environmental samples. A review. Anal. Chim. Acta 858, 1-15. doi:10.1016/j.aca.2014.07.002 
Olfson, M., King, M., Schoenbaum, M., 2015. Benzodiazepine use in the United States. JAMA psychiatry 72, 136-42. doi:10.1001/jamapsychiatry.2014.1763

Olofsson, U., Brorström-Lundén, E., Kylin, H., Haglund, P., 2013. Comprehensive mass flow analysis of Swedish sludge contaminants. Chemosphere 90, 28-35.

doi:10.1016/j.chemosphere.2012.07.002

Oppenheimer, J., Eaton, A., Badruzzaman, M., Haghani, A.W., Jacangelo, J.G., 2011. Occurrence and suitability of sucralose as an indicator compound of wastewater loading to surface waters in urbanized regions. Water Res. 45, 4019-4027. doi:10.1016/j.watres.2011.05.014

Ordóñez, E.Y., Quintana, J.B., Rodil, R., Cela, R., 2012. Determination of artificial sweeteners in water samples by solid-phase extraction and liquid chromatography-tandem mass spectrometry. J. Chromatogr. A 1256, 197-205. doi:10.1016/j.chroma.2012.07.073

Ort, C., van Nuijs, A.L.N., Berset, J.D., Bijlsma, L., Castiglioni, S., Covaci, A., de Voogt, P., Emke, E., Fatta-Kassinos, D., Griffiths, P., Hernández, F., González-Mariño, I., Grabic, R., KasprzykHordern, B., Mastroianni, N., Meierjohann, A., Nefau, T., Östman, M., Pico, Y., Racamonde, I., Reid, M., Slobodnik, J., Terzic, S., Thomaidis, N., Thomas, K. V., 2014. Spatial differences and temporal changes in illicit drug use in Europe quantified by wastewater analysis. Addiction 109, 1338-1352. doi:10.1111/add.12570

Ozturk, S., Ozturk, Y.E., Yeter, O., Alpertunga, B., 2015. Application of a validated LC-MS/MS method for JWH-073 and its metabolites in blood and urine in real forensic cases. Forensic Sci. Int. 257, 165-171. doi:10.1016/j.forsciint.2015.08.013

Papaseit, E., Farré, M., Schifano, F., Torrens, M., 2014. Emerging drugs in Europe. Curr. Opin. Psychiatry 27, 243-50. doi:10.1097/YCO.0000000000000071

Pawlik, E., Plässer, G., Mahler, H., Daldrup, T., 2012. Studies on the phase I metabolism of the new designer drug 3-fluoromethcathinone using rabbit liver slices. Int. J. Legal Med. 126, 231-240. doi:10.1007/s00414-011-0601-6

Pedrouzo, M., Borrull, F., Pocurull, E., Marcé, R.M., 2011. Drugs of abuse and their metabolites in waste and surface waters by liquid chromatography-tandem mass spectrometry. J. Sep. Sci. 34, 1091-1101. doi:10.1002/jssc.201100043

Pertwee, R.G., 2008. Ligands that target cannabinoid receptors in the brain: From THC to anandamide and beyond. Addict. Biol. 13, 147-159. doi:10.1111/j.1369-1600.2008.00108.x

Petrie, B., Barden, R., Kasprzyk-Hordern, B., 2015. A review on emerging contaminants in wastewaters and the environment: Current knowledge, understudied areas and recommendations for future monitoring. Water Res. 72, 3-27. doi:10.1016/j.watres.2014.08.053

Petrie, B., Youdan, J., Barden, R., Kasprzyk-Hordern, B., 2016. New Framework To Diagnose the Direct Disposal of Prescribed Drugs in Wastewater - A Case Study of the Antidepressant Fluoxetine. Environ. Sci. Technol. 50, 3781-3789. doi:10.1021/acs.est.6b00291

Pischon, T., 2009. Use of obesity biomarkers in cardiovascular epidemiology. Dis. Markers 26, 247-263. doi:10.3233/DMA-2009-0634

Plósz, B.G., Reid, M.J., Borup, M., Langford, K.H., Thomas, K. V., 2013. Biotransformation kinetics and sorption of cocaine and its metabolites and the factors influencing their estimation in wastewater. Water Res. 47, 2129-2140. doi:10.1016/j.watres.2012.12.034

Polesel, F., Andersen, H.R., Trapp, S., Plósz, B.G., 2016. Removal of antibiotics in biological wastewater treatment systems - A critical assessment using the Activated Sludge Modelling framework for Xenobiotics ( ASM-X ). Submitt. to Environ. Sci. Technol. acs.est.6b01899. doi:10.1021/acs.est.6b01899

Poste, G., 2011. Bring on the biomarkers. Nature 469, 156-157. doi:10.1038/469156a

Postigo, C., López de Alda, M.J., Barceló, D., 2010. Drugs of abuse and their metabolites in the Ebro River basin: Occurrence in sewage and surface water, sewage treatment plants removal efficiency, and collective drug usage estimation. Environ. Int. 36, 75-84. doi:10.1016/j.envint.2009.10.004 
Pozo, O.J., Ibañez, M., Sancho, J. V., Lahoz-Beneytez, J., Farre, M., Papaseit, E., de la Torre, R., Hernandez, F., 2014. Mass Spectrometric Evaluation of Mephedrone In Vivo Human Metabolism: Identification of Phase I and Phase II Metabolites, Including a Novel Succinyl Conjugate. Drug Metab. Dispos. 43, 248-257. doi:10.1124/dmd.114.061416

Preston, K.L., Epstein, D.H., Davoudzadeh, D., Huestis, M. a, 2003. Methadone and metabolite urine concentrations in patients maintained on methadone. J. Anal. Toxicol. 27, 332-341. doi:10.1093/jat/27.6.332

Prosser, J.M., Nelson, L.S., 2012. The Toxicology of Bath Salts: A Review of Synthetic Cathinones. J. Med. Toxicol. 8, 33-42. doi:10.1007/s13181-011-0193-Z

Prüfer, K., Racimo, F., Patterson, N., Jay, F., Sankararaman, S., Sawyer, S., Heinze, A., Renaud, G., Sudmant, P.H., de Filippo, C., Li, H., Mallick, S., Dannemann, M., Fu, Q., Kircher, M., Kuhlwilm, M., Lachmann, M., Meyer, M., Ongyerth, M., Siebauer, M., Theunert, C., Tandon, A., Moorjani, P., Pickrell, J., Mullikin, J.C., Vohr, S.H., Green, R.E., Hellmann, I., Johnson, P.L.F., Blanche, H., Cann, H., Kitzman, J.O., Shendure, J., Eichler, E.E., Lein, E.S., Bakken, T.E., Golovanova, L. V, Doronichev, V.B., Shunkov, M. V, Derevianko, A.P., Viola, B., Slatkin, M., Reich, D., Kelso, J., Pääbo, S., 2014. The complete genome sequence of a Neanderthal from the Altai Mountains. Nature 505, 43-9. doi:10.1038/nature12886

Racamonde, I., Quintana, J.B., Rodil, R., Cela, R., 2015. Application of polypropylene tubes as single-use and low-cost sorptive extraction materials for the determination of benzodiazepines and zolpidem in water samples. Microchem. J. 119, 58-65. doi:10.1016/j.microc.2014.10.011

Racamonde, I., Rodil, R., Quintana, J.B., Villaverde-de-Sáa, E., Cela, R., 2014. Determination of benzodiazepines, related pharmaceuticals and metabolites in water by solid-phase extraction and liquid-chromatography-tandem mass spectrometry. J. Chromatogr. A 1352, 69-79. doi:10.1016/j.chroma.2014.05.064

Ralla, B., Stephan, C., Meller, S., Dietrich, D., Kristiansen, G., Jung, K., 2014. Nucleic acid-based biomarkers in body fluids of patients with urologic malignancies. Crit. Rev. Clin. Lab. Sci. 8363, 1-32. doi:10.3109/10408363.2014.914888

Ramin, P., Brock, A.L., Polesel, F., Causanilles, A., Emke, E.., Voogt, P. De, Plósz, B.G., 2016. Transformation and sorption of illicit drug biomarkers in sewer systems: understanding the role of suspended solids in raw wastewater. Environ. Sci. Technol. doi:10.1021/acs.est.6b03049

Ramos, S., Homem, V., Alves, A., Santos, L., 2016. A review of organic UV-filters in wastewater treatment plants. Environ. Int. 86, 24-44. doi:10.1016/j.envint.2015.10.004

Reid, M.J., Baz-Lomba, J.A., Ryu, Y., Thomas, K. V., 2014a. Using biomarkers in wastewater to monitor community drug use: A conceptual approach for dealing with new psychoactive substances. Sci. Total Environ. 487, 651-658. doi:10.1016/j.scitotenv.2013.12.057

Reid, M.J., Derry, L., Thomas, K. V., 2014b. Analysis of new classes of recreational drugs in sewage: Synthetic cannabinoids and amphetamine-like substances. Drug Test. Anal. 6, 72-79. doi:10.1002/dta.1461

Reid, M.J., Langford, K.H., Mørland, J., Thomas, K. V., 2011. Analysis and interpretation of specific ethanol metabolites, ethyl sulfate, and ethyl glucuronide in sewage effluent for the quantitative measurement of regional alcohol consumption. Alcohol. Clin. Exp. Res. 35, 15931599. doi:10.1111/j.1530-0277.2011.01505.x

Reid, M.J., Thomas, K. V., 2016. Chapter 4: New psychoactive substances: analysis and sitespecific testing, in: Assessing Illicit Drugs in Wastewater: Advances in Wastewater-Based Drug Epidemiology, EMCDDA Insights 22. pp. 57-65.

Renwick, A.G., 1985. The fate of intense sweeteners in the body. Food Chem. 16, 281-301. doi:10.1016/0308-8146(85)90122-0

Renwick, A.G., Thompson, J.P., O'Shaughnessy, M., Walter, E.J., 2004. The metabolism of cyclamate to cyclohexylamine in humans during long-term administration. Toxicol. Appl. Pharmacol. 196, 367-380. doi:10.1016/j.taap.2004.01.013 
Rice, J., Yang, Z., Kasprzyk-Hordern, B., web-support@bath.ac.uk, 2015. Wastewater proteomics in community-wide molecular diagnostics of public health, in: Testing the Waters 2015: 2nd International Conference on Wastewater-Based Drug Epidemiology. University of Bath, Ascona.

Rico, M., Andrés-Costa, M.J., Picó, Y., 2016. Estimating population size in wastewater-based epidemiology. Valencia metropolitan area as a case study. J. Hazard. Mater. doi:10.1016/j.jhazmat.2016.05.079

Rifai, N., Gillette, M.A., Carr, S.A., 2006. Protein biomarker discovery and validation: the long and uncertain path to clinical utility. Nat. Biotechnol. 24, 971-983. doi:10.1038/nbt1235

Rizzati, V., Briand, O., Guillou, H., Gamet-Payrastre, L., 2016. Effects of pesticide mixtures in human and animal models: An update of the recent literature. Chem. Biol. Interact. 254, 231246. doi:10.1016/j.cbi.2016.06.003

Roberts, A., Renwick, A.G., Sims, J., Snodin, D.J., 2000. Sucralose metabolism and pharmacokinetics in man. Food Chem. Toxicol. 38, 31-41. doi:10.1016/S02786915(00)00026-0

Rodil, R., Quintana, J.B., Concha-Graña, E., López-Mahía, P., Muniategui-Lorenzo, S., PradaRodríguez, D., 2012. Emerging pollutants in sewage, surface and drinking water in Galicia (NW Spain). Chemosphere 86, 1040-1049. doi:10.1016/j.chemosphere.2011.11.053

Rodríguez-Alvarez, T., Racamonde, I., González-Mariño, I., Borsotti, A., Rodil, R., Rodríguez, I., Zuccato, E., Quintana, J.B., Castiglioni, S., 2015. Alcohol and cocaine co-consumption in two European cities assessed by wastewater analysis. Sci. Total Environ. 536, 91-8. doi:10.1016/j.scitotenv.2015.07.016

Rodríguez-Álvarez, T., Rodil, R., Cela, R., Quintana, J.B., 2014a. Ion-pair reversed-phase liquid chromatography-quadrupole-time-of-flight and triple-quadrupole-mass spectrometry determination of ethyl sulfate in wastewater for alcohol consumption tracing. J. Chromatogr. A 1328, 35-42. doi:10.1016/j.chroma.2013.12.076

Rodríguez-Álvarez, T., Rodil, R., Rico, M., Cela, R., Quintana, J.B., 2014b. Assessment of Local Tobacco Consumption by Liquid Chromatography-Tandem Mass Spectrometry Sewage Analysis of Nicotine and Its Metabolites, Cotinine and trans-3'-Hydroxycotinine, after Enzymatic Deconjugation. Anal. Chem. 86, 10274-10281. doi:10.1021/ac503330c

Rosal, R., Rodruíguez, A., Perdigón-Melón, J.A., Petre, A., García-Calvo, E., Gómez, M.J., Agüera, A., Fernández-Alba, Fernández-Alba, A.R., 2010. Occurrence of emerging pollutants in urban wastewater and their removal through biological treatment followed by ozonation. Water Res. 44, 578-588. doi:10.1016/j.watres.2009.07.004

Roth, B.L., Gibbons, S., Arunotayanun, W., Huang, X.P., Setola, V., Treble, R., Iversen, L., 2013. The Ketamine Analogue Methoxetamine and 3- and 4-Methoxy Analogues of Phencyclidine Are High Affinity and Selective Ligands for the Glutamate NMDA Receptor. PLoS One 8, $2-$ 6. doi:10.1371/journal.pone.0059334

Rousis, N.I., Zuccato, E., Castiglioni, S., 2016a. Monitoring population exposure to pesticides based on liquid chromatography-tandem mass spectrometry measurement of their urinary metabolites in urban wastewater: a novel biomonitoring approach. Sci. Total Environ. 571, 1349-1357. doi:10.1016/j.scitotenv.2016.07.036

Rousis, N.I., Zuccato, E., Castiglioni, S., 2016b. Wastewater-based epidemiology to assess human exposure to pyrethroid pesticides. Environ. Int. doi:10.1016/j.envint.2016.11.020

Ruhoy, I.S., Daughton, C.G., 2008. Beyond the medicine cabinet: An analysis of where and why medications accumulate. Environ. Int. 34, 1157-1169. doi:10.1016/j.envint.2008.05.002

Ryan, D., Robards, K., Prenzler, P.D., Kendall, M., 2011. Recent and potential developments in the analysis of urine: A review. Anal. Chim. Acta 684, 8-20. doi:10.1016/j.aca.2010.10.035

Rydevik, A., Lopardo, L., Petrie, B., Kasprzyk-Hordern, B., 2015. Wastewater profiling for community-wide human exposure assessment from environmental endocrine disrupting chemicals in personal care products, in: Testing the Waters 2015: 2nd International Conference 
on Wastewater-Based Drug Epidemiology, 2015-10-11 - 2015-10-15, Ascona.

Ryoo, S.., Lee, J., Yeo, J., Na, H.-K., Kim, Y.-K., Jang, H., Lee, J.H., Han, S.W., Lee, Y., Kim, V.N., Min, D.-H., 2013. Quantitative and Multiplexed MicroRNA Sensing in Living Cells Based on Peptide Nucleic Acid and Nano Graphene Oxide (PANGO). ACS Nano 7, 58825891.

Ryu, Y., Barceló, D., Barron, L.P., Bijlsma, L., Castiglioni, S., de Voogt, P., Emke, E., Hernández, F., Lai, F.Y., Lopes, A., de Alda, M.L., Mastroianni, N., Munro, K., O’Brien, J., Ort, C., Plósz, B.G., Reid, M.J., Yargeau, V., Thomas, K. V, 2016. Comparative measurement and quantitative risk assessment of alcohol consumption through wastewater-based epidemiology: An international study in 20 cities. Sci. Total Environ. 565, 977-983. doi:10.1016/j.scitotenv.2016.04.138

Ryu, Y., Reid, M.J., Thomas, K. V., 2015. Liquid chromatography-high resolution mass spectrometry with immunoaffinity clean-up for the determination of the oxidative stress biomarker 8-iso-prostaglandin F2alpha in wastewater. J. Chromatogr. A 1409, 146-151. doi:10.1016/j.chroma.2015.07.060

Sánchez-Flores, M., Pásaro, E., Bonassi, S., Laffon, B., Valdiglesias, V., 2015. H2AX assay as DNA damage biomarker for human population studies: Defining experimental conditions. Toxicol. Sci. 144, 406-413. doi:10.1093/toxsci/kfv011

Santos, J.L., Aparicio, I., Callejón, M., Alonso, E., 2009. Occurrence of pharmaceutically active compounds during 1-year period in wastewaters from four wastewater treatment plants in Seville (Spain). J. Hazard. Mater. 164, 1509-1516. doi:10.1016/j.jhazmat.2008.09.073

Sardesai, V.M., Waldshan, T.H., 1991. Natural and synthetic intense sweeteners. J. Nutr. Biochem. 2, 236-244. doi:10.1016/0955-2863(91)90081-F

Schenzel, J., Hungerbühler, K., Bucheli, T.D., 2012. Mycotoxins in the environment: II. Occurrence and origin in Swiss river waters. Environ. Sci. Technol. 46, 13076-13084. doi:10.1021/es301558v

Schenzel, J., Schwarzenbach, R.P., Bucheli, T.D., 2010. Multi-residue screening method to quantify mycotoxins in aqueous environmental samples. J. Agric. Food Chem. 58, 11207-11217. doi:10.1021/jf102737q

Schneider, H., Glatt, H., 2004. Sulpho-conjugation of ethanol in humans in vivo and by individual sulphotransferase forms in vitro. Biochem. J. 383, 543-549. doi:10.1042/BJ20040925

Schreder, E.D., La Guardia, M.J., 2014. Flame retardant transfers from U.S. households (dust and laundry wastewater) to the aquatic environment. Environ. Sci. Technol. 48, 11575-11583. doi:10.1021/es502227h

Schwartz, R., Milteer, R., LeBeau, M.A., 2000. Drug-facilitated sexual assault ("Date Rape"). South. Med. J. 93, 558-561.

Seely, K.A., Lapoint, J., Moran, J.H., Fattore, L., 2012. Spice drugs are more than harmless herbal blends: A review of the pharmacology and toxicology of synthetic cannabinoids. Prog. NeuroPsychopharmacology Biol. Psychiatry 39, 234-243. doi:10.1016/j.pnpbp.2012.04.017

Senta, I., Gracia-Lor, E., Borsotti, A., Zuccato, E., Castiglioni, S., 2015a. Wastewater analysis to monitor use of caffeine and nicotine and evaluation of their metabolites as biomarkers for population size assessment. Water Res. 74, 23-33. doi:10.1016/j.watres.2015.02.002

Senta, I., Krizman, I., Ahel, M., Terzic, S., 2015b. Multiresidual analysis of emerging amphetamine-like psychoactive substances in wastewater and river water. J. Chromatogr. A 1425, 204-212. doi:10.1016/j.chroma.2015.11.043

Senta, I., Krizman, I., Ahel, M., Terzic, S., 2014. Assessment of stability of drug biomarkers in municipal wastewater as a factor influencing the estimation of drug consumption using sewage epidemiology. Sci. Total Environ. 487, 659-665. doi:10.1016/j.scitotenv.2013.12.054

Sharma, A., Schorr, U., Thiede, H., Distler, A., 1993. Effect of dietary salt restriction on urinary serotonin and 5-hydroxyindoleacetic acid excretion in man. J Hypertens 1381-1386.

Shima, N., Katagi, M., Kamata, H., Matsuta, S., Sasaki, K., Kamata, T., Nishioka, H., Miki, A., 
Tatsuno, M., Zaitsu, K., Ishii, A., Sato, T., Tsuchihashi, H., Suzuki, K., 2014. Metabolism of the newly encountered designer drug $\alpha$ - pyrrolidinovalerophenone in humans: Identification and quantitation of urinary metabolites. Forensic Toxicol. 32, 59-67. doi:10.1007/s11419-0130202-9

Silva, M.J., Samandar, E., Reidy, J.A., Hauser, R., Needham, L.L., Calafat, A.M., 2007. Metabolite profiles of Di-n-butyl phthalate in humans and rats. Environ. Sci. Technol. 41, 7576-7580. doi:10.1021/es071142x

Singh, S.P., Azua, A., Chaudhary, A., Khan, S., Willett, K.L., Gardinali, P.R., 2010. Occurrence and distribution of steroids, hormones and selected pharmaceuticals in South Florida coastal environments. Ecotoxicology 19, 338-350. doi:10.1007/s10646-009-0416-0

Singh, S.P., Gardinali, P.R., 2006. Trace determination of 1-aminopropanone, a potential marker for wastewater contamination by liquid chromatography and atmospheric pressure chemical ionization-mass spectrometry. Water Res. 40, 588-594. doi:10.1016/j.watres.2005.11.036

Smith, H.S., 2009. Opioid metabolism. Mayo Clin. Proc. 84, 613-624. doi:10.4065/84.7.613

Snip, L.J.P., Flores-Alsina, X., Aymerich, I., Rodríguez-Mozaz, S., Barceló, D., Plósz, B.G., Corominas, L., Rodriguez-Roda, I., Jeppsson, U., Gernaey, K. V., 2016. Generation of synthetic influent data to perform (micro)pollutant wastewater treatment modelling studies. Sci. Total Environ. 569-570, 278-290. doi:10.1016/j.scitotenv.2016.05.012

Staack, R.F., Fehn, J., Maurer, H.H., 2003. New designer drug p-methoxymethamphetamine: Studies on its metabolism and toxicological detection in urine using gas chromatography-mass spectrometry. J. Chromatogr. B Anal. Technol. Biomed. Life Sci. 789, $27-41$. doi:10.1016/S1570-0232(02)01018-8

Staack, R.F., Fritschi, G., Maurer, H.H., 2001. GC-MS studies on the metabolism and on the toxicological analysis of the new piperazine-like designer drugs BZP, MDBP, TFMPP, mCPP, MeOPP, Proceedings of the 39th International TIAFT Meeting in Prague, Czech Republic.

Staack, R.F., Maurer, H.H., 2005. Metabolism of designer drugs of abuse. Curr Drug Metab 6, 259274. doi:10.2174/1389200054021825

Staub, C., Marset, M., Mino, a, Mangin, P., 2001. Detection of acetylcodeine in urine as an indicator of illicit heroin use: method validation and results of a pilot study. Clin. Chem. 47, $301-7$.

Takada, H., Eganhouse, R., 1998. Molecular markers of anthropogenic waste, in: Meyers, R. A. Ed. Encyclopedia of Environmental Analysis and Remediation. John Wiley \& Sons, Inc., New York, NY, USA. John Wiley \& Sons, Inc. pp. 2883-2940.

Thai, P.K., Jiang, G., Gernjak, W., Yuan, Z., Lai, F.Y., Mueller, J.F., 2014. Effects of sewer conditions on the degradation of selected illicit drug residues in wastewater. Water Res. 48, 538-547. doi:10.1016/j.watres.2013.10.019

Thai, P.K., Lai, F.Y., Edirisinghe, M., Hall, W., Bruno, R., O’Brien, J.W., Prichard, J., Kirkbride, K.P., Mueller, J.F., 2016. Monitoring temporal changes in use of two cathinones in a large urban catchment in Queensland, Australia. Sci. Total Environ. 545-546, 250-255. doi:10.1016/j.scitotenv.2015.12.038

Thomaidis, N.S., Gago-Ferrero, P., Ort, C., Maragou, N.C., Alygizakis, N.A., Borova, V.L., Dasenaki, M.E., 2016. Reflection of Socioeconomic Changes in Wastewater: Licit and Illicit Drug Use Patterns. Environ. Sci. Technol. acs.est.6b02417. doi:10.1021/acs.est.6b02417 Thomas, K. V., Bijlsma, L., Castiglioni, S., Covaci, A., Emke, E., Grabic, R., Hernández, F., Karolak, S., Kasprzyk-Hordern, B., Lindberg, R.H., Lopez de Alda, M., Meierjohann, A., Ort, C., Pico, Y., Quintana, J.B., Reid, M., Rieckermann, J., Terzic, S., van Nuijs, A.L.N., de Voogt, P., 2012. Comparing illicit drug use in 19 European cities through sewage analysis. Sci. Total Environ. 432, 432-439. doi:10.1016/j.scitotenv.2012.06.069

Thomas, K. V., Reid, M.J., 2011. What Else Can the Analysis of Sewage for Urinary Biomarkers Reveal About Communities? Environ. Sci. Technol. 45, 7611-7612. doi:10.1021/es202522d Thomsen, P.F., Willerslev, E., 2015. Environmental DNA - An emerging tool in conservation for 
monitoring past and present biodiversity. Biol Conserv 183, 4-18.

Tipirisetti, N.R., Govatati, S., Pullari, P., Malempati, S., Thupurani, M.K., Perugu, S., Guruvaiah, P., Rao K, L., Digumarti, R.R., Nallanchakravarthula, V., Bhanoori, M., Satti, V., 2014. Mitochondrial control region alterations and breast cancer risk: A study in south Indian population. PLoS One 9, 1-8. doi:10.1371/journal.pone.0085363

Toxicological profile for di(2-ethylhexyl)phthalate (DEHP), 2002. . U.S Dep. Heal. Hum. Serv. Public Heal. Serv. Agency Toxic Subst. Dis. Regist.

Toxicological profile for Di-n-Phthalate, 2001. . U.S Dep. Heal. Hum. Serv. Public Heal. Serv. Agency Toxic Subst. Dis. Regist.

Tran, N.H., Hu, J., Ong, S.L., 2013. Simultaneous determination of PPCPs, EDCs, and artificial sweeteners in environmental water samples using a single-step SPE coupled with HPLCMS/MS and isotope dilution. Talanta 113, 82-92. doi:10.1016/j.talanta.2013.03.072

Trunnelle, K.J., Bennett, D.H., Tancredi, D.J., Gee, S.J., Stoecklin-Marois, M.T., Hennessy-Burt, T.E., Hammock, B.D., Schenker, M.B., 2013. Pyrethroids in house dust from the homes of farm worker families in the MICASA study. Environ. Int. 61, 57-63. doi:10.1016/j.envint.2013.09.007

Tscharke, B.J., Chen, C., Gerber, J.P., White, J.M., 2016. Temporal trends in drug use in Adelaide, South Australia by wastewater analysis. Sci. Total Environ. 565, 384-391. doi:10.1016/j.scitotenv.2016.04.183

Tsui, M.M.P., Leung, H.W., Lam, P.K.S., Murphy, M.B., 2014. Seasonal occurrence, removal efficiencies and preliminary risk assessment of multiple classes of organic UV filters in wastewater treatment plants. Water Res. 53, 58-67. doi:10.1016/j.watres.2014.01.014

Tsujikawa, K., Mikuma, T., Kuwayama, K., Miyaguchi, H., Kanamori, T., Iwata, Y.T., Inoue, H., 2012. Degradation pathways of 4-methylmethcathinone in alkaline solution and stability of methcathinone analogs in various pH solutions. Forensic Sci. Int. 220, 103-110. doi:10.1016/j.forsciint.2012.02.005

Tsutsumi, H., Katagi, M., Miki, A., Shima, N., Kamata, T., Nishikawa, M., Nakajima, K., Tsuchihashi, H., 2005. Development of simultaneous gas chromatography-mass spectrometric and liquid chromatography-electrospray ionization mass spectrometric determination method for the new designer drugs, N-benzylpiperazine (BZP), 1-(3-trifluoromethylphenyl)piperazine (TFMPP). J. Chromatogr. B Anal. Technol. Biomed. Life Sci. 819, 315-322. doi:10.1016/j.jchromb.2005.02.016

Turner, N.W., Bramhmbhatt, H., Szabo-Vezse, M., Poma, A., Coker, R., Piletsky, S.A., 2015. Analytical methods for determination of mycotoxins: An update (2009-2014). Anal. Chim. Acta 901, 12-33. doi:10.1016/j.aca.2015.10.013

Udert, K.M., Larsen, T.A., Gujer, W., 2006. Fate of major compounds in source-separated urine. Water Sci. Technol. 54, 413-420. doi:10.2166/wst.2006.921

UNODC, U.N.O. on D. and C., 2015. World Drug Report. doi:10.1017/CBO9781107415324.004

Uralets, V., Rana, S., Morgan, S., Ross, W., 2014. Testing for designer stimulants: Metabolic profiles of 16 synthetic cathinones excreted free in human urine. J. Anal. Toxicol. 38, 233241. doi:10.1093/jat/bku021

USFDA, 2006. Artificial sweeteners: No calories ... sweet! FDA Consum, The US Food and Drug Adminstration (USFDA). USFDA 40, 27-28.

Valle-Sistac, J., Molins-Delgado, D., Díaz, M., Ibáñez, L., Barceló, D., Silvia Díaz-Cruz, M., 2016. Determination of parabens and benzophenone-type UV filters in human placenta: First description of the existence of benzyl paraben and benzophenone-4. Environ. Int. 88, 243-249. doi:10.1016/j.envint.2015.12.034

Valls, M., Bayona, J.M., Albaigés, J., 1989. Use of trialkylamines as an indicator of urban sewage in sludges, coastal waters and sediments. Nature 337, 722-724.

Van den Eede, N., Heffernan, A.L., Aylward, L.L., Hobson, P., Neels, H., Mueller, J.F., Covaci, A., 2015. Age as a determinant of phosphate flame retardant exposure of the Australian population 
and identification of novel urinary PFR metabolites. Environ. Int. 74, 1-8.

doi:10.1016/j.envint.2014.09.005

Van den Eede, N., Maho, W., Erratico, C., Neels, H., Covaci, A., 2013. First insights in the metabolism of phosphate flame retardants and plasticizers using human liver fractions. Toxicol. Lett. 223, 9-15. doi:10.1016/j.toxlet.2013.08.012

van Nuijs, A.L., Gheorghe, A., Jorens, P.G., Maudens, K., Neels, H., Covaci, A., 2014. Optimization, validation, and the application of liquid chromatography-tandem mass spectrometry for the analysis of new drugs of abuse in wastewater. Drug Test. Anal. 6, 861867.

van Nuijs, A.L.N., Castiglioni, S., Tarcomnicu, I., Postigo, C., de Alda, M.L., Neels, H., Zuccato, E., Barcelo, D., Covaci, A., 2011a. Illicit drug consumption estimations derived from wastewater analysis: A critical review. Sci. Total Environ. 409, 3564-3577. doi:10.1016/j.scitotenv.2010.05.030

van Nuijs, A.L.N., Covaci, A., Beyers, H., Bervoets, L., Blust, R., Verpooten, G., Neels, H., Jorens, P.G., 2015. Do concentrations of pharmaceuticals in sewage reflect prescription figures?

Environ. Sci. Pollut. Res. 22, 9110-9118. doi:10.1007/s11356-014-4066-2

van Nuijs, A.L.N., Mougel, J.F., Tarcomnicu, I., Bervoets, L., Blust, R., Jorens, P.G., Neels, H., Covaci, A., 2011b. Sewage epidemiology - A real-time approach to estimate the consumption of illicit drugs in Brussels, Belgium. Environ. Int. 37, 612-621. doi:10.1016/j.envint.2010.12.006

Van Nuijs, A.L.N., Pecceu, B., Theunis, L., Dubois, N., Charlier, C., Jorens, P.G., Bervoets, L., Blust, R., Meulemans, H., Neels, H., Covaci, A., 2009. Can cocaine use be evaluated through analysis of wastewater? A nation-wide approach conducted in Belgium. Addiction 104, 734 741. doi:10.1111/j.1360-0443.2009.02523.x

Vazquez-Roig, P., Kasprzyk-Hordern, B., Blasco, C., Pico', Y., 2014. Stereoisomeric profiling of drugs of abuse and pharmaceuticals in wastewaters of Valencia (Spain). Sci. Total Environ. 494-495, 49-57. doi:10.1016/j.scitotenv.2014.06.098

Verlicchi, P., Al Aukidy, M., Zambello, E., 2012. Occurrence of pharmaceutical compounds in urban wastewater: Removal, mass load and environmental risk after a secondary treatment-A review. Sci. Total Environ. 429, 123-155. doi:10.1016/j.scitotenv.2012.04.028

Wang, C., Yang, L., Wang, S., Zhang, Z., Yu, Y., Wang, M., Cromie, M., Gao, W., Wang, S.-L., 2016. The classic EDCs, phthalate esters and organochlorines, in relation to abnormal sperm quality: a systematic review with meta-analysis. Sci. Rep. 6, 19982. doi:10.1038/srep19982

Wang, P., Wu, H., Dai, Z., Zou, X., 2012. Picomolar level profiling of the methylation status of the p53 tumor suppressor gene by a label-free electrochemical biosensor. Chem. Commun. 48, 10754. doi:10.1039/c2 cc35615e

Warth, B., Sulyok, M., Krska, R., 2013. LC-MS/MS-based multibiomarker approaches for the assessment of human exposure to mycotoxins. Anal. Bioanal. Chem. 405, 5687-5695. doi:10.1007/s00216-013-7011-1

Webb, A.L., Kruczkiewicz, P., Selinger, L.B., Inglis, G.D., Taboada, E.N., 2015. Development of a comparative genomic fingerprinting assay for rapid and high resolution genotyping of Arcobacter butzleri. BMC Microbiol 15, 94. doi:10.1186/s12866-015-0426-4

Welter-Luedeke, J., Maurer, H.H., 2015. New Psychoactive Substances: Chemistry, Pharmacology, Metabolism, and Detectability of Amphetamine Derivatives with Modified Ring Systems.

Ther. Drug Monit. 38, 4-11. doi:10.1097/FTD.0000000000000240

Wettstein, F.E., Bucheli, T.D., 2010. Poor elimination rates in waste water treatment plants lead to continuous emission of deoxynivalenol into the aquatic environment. Water Res. 44, 41374142. doi:10.1016/j.watres.2010.05.038

WHO Food Additive Series No. 52, 2004. Safety evaluation of certain food additives and contaminants.

Wohlfarth, A., Scheidweiler, K.B., Chen, X., Liu, H., Huestis, M.A., 2013. Qualitative 
Confirmation of 9 Synthetic Cannabinoids and 20 Metabolites in Human Urine Using LC-MS/MS and Library Search. Anal. Chem. 85, 3730-3738.

World Health Organization, 2015. WHO global report on trends in prevalence of tobacco smoking. World Health Organization, 2014. WHO global status report on alcohol and health.

Wurst, F.M., Dresen, S., Allen, J.P., Wiesbeck, G., Graf, M., Weinmann, W., 2006. Ethyl sulphate: A direct ethanol metabolite reflecting recent alcohol consumption. Addiction 101, 204-211. doi:10.1111/j.1360-0443.2005.01245.x

Yang, Z., D’Uriac, M.A., Goggins, S., Kasprzyk-Hordern, B., Thomas, K. V., Frost, C.G., Estrela, P., 2015a. A novel DNA biosensor using a ferrocenyl intercalator applied to the potential detection of human population biomarkers in wastewater. Environ. Sci. Technol. 49, 56095617. doi:10.1021/acs.est.5b00637

Yang, Z., Kasprzyk-Hordern, B., Frost, C.G., Estrela, P., Thomas, K. V., 2015b. Community sewage sensors for monitoring public health. Environ. Sci. Technol. 49, 5845-5846. doi:10.1021/acs.est.5b01434

Yang, Z., Kasprzyk-Hordern, B., Goggins, S., Frost, C.G., Estrela, P., 2015c. A novel immobilization strategy for electrochemical detection of cancer biomarkers: DNA-directed immobilization of aptamer sensors for sensitive detection of prostate specific antigens. Analyst 140, 2628-2633. doi:10.1039/C4AN02277G

Yuan, S.-F., Liu, Z.-H., Huang, R.-P., Yin, H., Dang, Z., 2015. Levels of six antibiotics used in China estimated by means of wastewater-based epidemiology. Water Sci. Technol. doi:10.2166/wst.2015.526

Yusa, V., Millet, M., Coscolla, C., Roca, M., 2015. Analytical methods for human biomonitoring of pesticides. A review. Anal. Chim. Acta 891, 15-31. doi:10.1016/j.aca.2015.05.032

Zaitsu, K., Katagi, M., Tatsuno, M., Sato, T., Tsuchihashi, H., Suzuki, K., 2011. Recently abused ??-keto derivatives of 3,4- methylenedioxyphenylalkylamines: A review of their metabolisms and toxicological analysis. Forensic Toxicol. 29, 73-84. doi:10.1007/s1 1419-0110111-8

Zawilska, J.B., Andrzejczak, D., 2015. Next generation of novel psychoactive substances on the horizon-a complex problem to face. Drug Alcohol Depend. 157, 1-17. doi:10.1016/j.drugalcdep.2015.09.030

Zhang, Z., Sun, L., Hu, Y., Jiao, J., Hu, J., 2013. Inverse antagonist activities of parabens on human oestrogen-related receptor $\gamma(\mathrm{ERR} \gamma)$ : In vitro and in silico studies. Toxicol. Appl. Pharmacol. 270, 16-22. doi:10.1016/j.taap.2013.03.030

Zhong, R., Wang, H., Wu, X., Cao, Y., He, Z., He, Y., Liu, J., 2013. In vitro investigation of the effect of plasticizers on the blood compatibility of medical grade plasticized poly (vinyl chloride). J. Mater. Sci. Mater. Med. 24, 1985-1992. doi:10.1007/s10856-013-4950-1

Zhou, N., Lin, X., Wang, S., Wang, H., Li, W., Tao, Z., Xu, A., 2014. Environmental Surveillance for Human Astrovirus in Shandong Province, China in 2013. Sci. Rep. 4, 7539. doi:10.1038/srep07539

Zolfaghari, M., Drogui, P., Seyhi, B., Brar, S.K., Buelna, G., Dubé, R., 2014. Occurrence, fate and effects of Di (2-ethylhexyl) Phthalate in wastewater treatment plants: a review. Environ. Pollut. 194, 281-93. doi:10.1016/j.envpol.2014.07.014

Zuccato, E., Castiglioni, S., Senta, I., Borsotti, A., Genetti, B., Andreotti, A., Pieretti, G., Serpelloni, G., 2016. Population surveys compared with wastewater analysis for monitoring illicit drug consumption in Italy in 2010-2014. Drug Alcohol Depend. 161, 178-188. doi:10.1016/j.drugalcdep.2016.02.003

Zuccato, E., Chiabrando, C., Castiglioni, S., Bagnati, R., Fanelli, R., 2008. Estimating community drug abuse by wastewater analysis. Environ. Health Perspect. 116, 1027-1032. doi:10.1289/ehp.11022

Zuccato, E., Chiabrando, C., Castiglioni, S., Calamari, D., Bagnati, R., Schiarea, S., Fanelli, R., 2005. Cocaine in surface waters: a new evidence-based tool to monitor community drug abuse. 
Environ. Heal. A Glob. Access Sci. Source 4, 14. doi:10.1186/Received Zuetenhorst, J.M., 2004. Daily Cyclic Changes in the Urinary Excretion of 5-Hydroxyindoleacetic Acid in Patients with Carcinoid Tumors. Clin. Chem. 50, 1634-1639. doi:10.1373/clinchem.2004.032151 